\title{
SOLUBLE AND MEMBRANE-ASSOCIATED FORMS OF ACID PHOSPHATASE ASSOCIATED WITH THE LYSOSOMAL FRACTION OF RAT LIVER
}

\author{
Barbara Furin Sloat* and John M. Allen \\ Department of Zoology \\ The University of Michigan \\ Ann Arbor, Mich.
}

\section{INTRODUCTION}

As initially formulated (de Duve, 1959), the lysosome concept held that the hydrolytic enzymes associated with lysosomes are contained within the particles and that constraint from hydrolytic action is provided by the particle membrane, which acts as a barrier to enzyme-substrate interaction. Rupture of the lysosomal membrane, within this context, should result in the simultaneous release of all internal enzymes in a soluble and fully active form, rendering them accessible to substrates of the cytoplasm. A disparity between the total acid phosphatase activity of the intact lysosomal fraction and the unsedimentable activity of the released enzyme was noted, however, as early as 1951 (Berthet et al., 1951). This discrepancy was accounted for on the basis of secondary adsorption of enzyme to lysosomal structure (Berthet et al., 1951; Appelmans \& de Duve, 1958; de Duve, 1959).

Recently, morphological and biochemical data have become available suggesting that this view of the association between the lysosomal hydrolases and lysosomal structure may have to be revised. Electron microscopic observations show that the lysosome may possess a complex internal structure (Novikoff et al., 1956; Van Lancker \& Sempoux, 1958; Daems \& Van Rijssel, 1961; Koenig, 1962), and biochemical determinations suggest that lysosomes may possess structure-bound enzymes that are not released by simple physical disruption. An inability to release all acid phosphatase from rat liver lysosomes by physical disruption was reported by Shibko and Tappel (1963). Similarly, Allen and Gockerman (1964) were unable to effect total release of acid phosphatase from rat liver lysosomes by physical disruption, but did achieve total solubilization in the presence of Triton X-100. These authors further demonstrated the presnce of two electrophoretically distinct acid phosphatases in their mitochondrial-lysosomal fraction. These forms exhibited differential release properties, one being released by physical disruption of the particles and the other only after treatment of the fraction with Triton X-100. In addition to these instances, other lysosomal enzymes reported to be bound in part to lysosomal structure include aryl sulfatase A (Ugazio \& Pani, 1963), an esterase (Shibko \& Tappel, 1964), $\beta$-acetyl glucosaminidase (Weissman $e t$ al., 1967), and $\beta$-glucosidase (Beck \& Tappel, 1968).

This paper deals with a more definitive localization of a bound form of acid phosphatase to the lysosomal fraction of rat liver, with some physical and biochemical properties of the bound and soluble acid phosphatase of this fraction, and with the behavior of these enzymes in the lysosomes of regenerating rat liver.

- Portions of this work were submitted in partial fulfillment of the requirements for the $\mathrm{Ph} . \mathrm{D}$. degree. The work was supported by funds from an NIH training grant in the Department of Zoology, The University of Michigan, (NIH 5T 01GM00989). 


\section{Materials and Methods \\ Preparation of Liver Homogenates}

Normal tissue. Normal tissue used in quantitative and electrophoretic studies was obtained from 300 to 400 -gram albino male rats. Animals were fed a diet of Purina Lab Chow and water ad libitum. After a starvation period of 12 to 18 hours, animals were sacrificed by cervical dislocation. The liver was removed immediately, weighed, and an initial $20 \%(\mathrm{w} / \mathrm{v})$ homogenate prepared by bringing $20 \mathrm{~g}$ of tissue to a final volume of $100 \mathrm{ml}$ with $0.25 \mathrm{M}$ sucrose (Merck, reagent grade). Tissue was homogenized at $\mathrm{O}^{\circ} \mathrm{C}$ in a smooth glass homogenizer with a Teflon pestle using 5 to 8 up-down strokes at $1200 \mathrm{rev} / \mathrm{min}$.

Regenerated tissue. Animals were partially hepatectomized under Nembutal anesthesia (Merck, $20 \mathrm{mg} / \mathrm{kg}$ body weight) according to the method of Higgins and Anderson (1931). At the time of partial hepatectomy, the median and left lateral lobes were ligated and removed. This tissue was homogenized as above and utilized as control tissue. During the first 24 hours after the operation, animals were provided with $20 \%$ dextrose (Mallinckrodt analytical) ad libitum. After this period, food and water were given as usual. After the required regeneration period, animals were sacrificed and homogenates prepared as previously described.

\section{Differential Centrifugation}

Normal and regenerated whole tissue homogenates were subjected to differential centrifugation at $4^{\circ} \mathrm{C}$ according to one of the following schemes. Centrifugation times and $g$ values are designated exclusive of acceleration and deceleration times and are based on average r-values.

\section{Scheme 1:}

Nuclear fraction. Whole homogenates were centrifuged at $480 \times g$ for 10 minutes followed by two washes ( 5 up-down strokes each), resuspensions, and recentrifugations at $270 \times g$ for 10 minutes each. The washed pellet was resuspended to starting volume in $0.25 \mathrm{M}$ sucrose to yield a final $20 \%$ fraction. All other pellets were resuspended to starting volume in the same manner.

Mitochondrial-lysosomal fraction. The combined supernatants from the nuclear step were centrifuged at $22,000 \times g$ for 30 minutes to sediment mitochondria and lysosomes.

Microsomal-soluble fraction. The supernatant remaining after the mitochondrial-lysosomal centrifugation was designated the microsomal-soluble fraction. All centrifugations were carried out in a Servall RC 2 refrigerated centrifuge equipped with an SS-34 rotor.

\section{Scheme 2:}

Nuclear fraction. Whole homogenates were centrifuged at $270 \times g$ for 10 minutes. Two resuspensions (homogenized with 8 up-down strokes at 1,200 rev/ $\mathrm{min}$ ) and recentrifugations followed at the same speed and time. The washed pellet was brought to starting volume with $0.25 \mathrm{M}$ sucrose.

Mitochondrial fraction. The combined supernatants from the nuclear sedimentation were centrifuged at $2,500 \times g$ for 10 minutes. The pellet was resuspended, homogenized by hand, and recentrifuged at the same speed and time to yield the final mitochondrial pellet. Resuspension to starting volume with $0.25 \mathrm{M}$ sucrose followed. 
Lysosomal fraction. Mitochondrial supernatants were combined and centrifuged at $8,700 \times g$ for 20 minutes. The lysosomal pellet was brought to starting volume in $0.25 \mathrm{M}$ sucrose as described. All steps to this point were carried out using a Servall refrigerated centrifuge (RC 2) equipped with an SS-34 rotor. Subsequent fractions were obtained using a Spinco Ti50 rotor in a Spinco L2-50 centrifuge.

Microsomal fraction. The lysosomal supernatant was centrifuged at 165,000 $\times g$ for 60 minutes to yield a microsomal pellet that was resuspended to starting volume in $0.25 \mathrm{M}$ sucrose.

Soluble fraction. The supernatant from the microsomal centrifugation constituted the soluble fraction.

Recoveries of enzymatic activity, calculated as percent of whole homogenate activity present in summed fractions, averaged $98 \%$ for acid phosphatase; $98 \%$ for glucose-6-phosphatase; and $100 \%$ for succinic dehydrogenase.

\section{Density Gradient Centrifugations}

Gradients were made and fractions collected using a Buchler density gradient device following the method of Martin and Ames (1961). Linearity of the gradients was confirmed by spectrophotometric measurement of dichlorophenolindophenol (DCIP) incorporated into gradients during preparation. Three types of gradients were utilized:

1. Density equilibrium centrifugation was carried out at $4^{\circ} \mathrm{C}$ according to Beaufay et al., (1964), using a Spinco SW 39 rotor in a Spinco Model L2-50 centrifuge. Sucrose gradients of density 1.12 to 1.26 were prepared and stored 12 to 18 hours at $4^{\circ} \mathrm{C}$ before use. Four hundred $\mu$ l samples of $20 \%$ homogenates from which nuclei had been removed were layered on $4.6 \mathrm{ml}$ gradients to yield a final tube volume of $5.0 \mathrm{ml}$. Centrifugation at $124,000 \times g$ was carried out at $4^{\circ} \mathrm{C}$ for 2.5 hours.

2. Sedimentation behavior of released soluble and bound forms of acid phosphatase was examined employing 5 to $20 \%$ sucrose: water gradients (density 1.017 to 1.074) according to the method of Martin and Ames (1961). One hundred $\mu$ l of a $20 \%$ sample were layered on gradients prepared 12 to 18 hours before use and stored at $4^{\circ} \mathrm{C}$. Final tube volume was $4.7 \mathrm{ml}$. Centrifugation was carried out at $4^{\circ} \mathrm{C}$ for 4 and 8 hours at $124,000 \times g$ using a Spinco L 2-50 centrifuge equipped with a Spinco SW 39 rotor.

3. Velocity density gradient centrifugation experiments were carried out using $0.25 \mathrm{M}$ to $0.7 \mathrm{M}$ sucrose: water gradients (density based on sucrose concentration, 1.032 to 1.090 . Gradients were made $1.0 \mathrm{M}$ with $\mathrm{KCl}$ (Baker reagent grade) and prepared at $4^{\circ} \mathrm{C}$ just prior to use. A $200 \mu$ l cushion of $2.0 \mathrm{M}$ sucrose was utilized to facilitate collection of sedimented material. Prior to layering, homogenates were made $0.2 \mathrm{M}$ with respect to sucrose and $1.0 \mathrm{M}$ with $\mathrm{KCl}$. Two hundred $\mu \mathrm{l}$ of a $4 \%$ homogenate from which the nuclei had been removed were layered on gradients to yield a tube volume of $5.0 \mathrm{ml}$. Centrifugation was carried out at $4^{\circ} \mathrm{C}$ for 20 minutes at $4,000,8,000$, and $124,000 \times g$ using a Spinco L2-50 centrifuge equipped with a Spinco SW 39 rotor.

Data are presented as relative activities, calculated as the enzyme activity present in each fraction divided by the calculated mean enzyme activity per fraction. Sedimentation behavior of particles as determined by marker enzyme positions in the gradients is described in terms of median density position in centimeters from the axis of rotation (Hogeboom \& Kuff, 1954). 


\section{Enzyme Assays}

Biochemical determination of enzyme activity was made according to the following methods. For all assays, substrate was not limiting. Reaction rates were linear with time and enzyme concentration.

Acid phosphatase activity was determined using (a) $\alpha$-naphthyl acid phosphate (Sigma), (b) p-nitrophenyl phosphate (Sigma), and (c) sodium $\beta$-glycerophosphate (Sigma) as substrates.

(a) $\alpha$-naphthol liberated enzymatically from sodium $\alpha$-naphthyl acid phosphate at $\mathrm{pH} 5.0$ was determined according to the method of Allen and Gockerman (1964).

(b) p-nitrophenol liberated enzymatically at $\mathrm{pH} 5.0$ from $p$-nitrophenyl phosphate was determined according to Sigma Technical Bulletin 104 (1963).

(c) Measurement of phosphate produced by enzymatic hydrolysis of $\beta$-glycerophosphate at pH 5.0 was accomplished by a modification of the method of Shinowara et al. (1942) and Dryer et al. (1957). The reaction mixture contained sodium acetate-acetic acid buffer, $\mathrm{pH} 5.0,45 \mathrm{mM}$ and sodium $\beta$-glycerophosphate, $34 \mathrm{mM}$. After incubation at $37^{\circ} \mathrm{C}$, the reaction was stopped by adding 30\% trichloroacetic acid (Baker), two parts to ten parts of reaction mixture. Precipitated protein was removed by centrifugation. Samples of TCA-supernatant were assayed for inorganic phosphate using the following proportions of reactants: ammonium molybdate (Baker), $0.04 \mathrm{M}, 1$ part; TCA-supernatant, 3 parts; $N$-phenyl-p-phenylenediamine monohydrochloride (Eastman), $0.05 \mathrm{M}$ in $1 \%$ sodium bisulfite (Mallinckrodt), 6 parts. Color was developed at room temperature for 10 minutes. Optical density was measured at $700 \mathrm{~m} \mu$ with a Coleman Model 6A spectrophotometer.

Glucose-6-phosphatase activity was determined by measuring inorganic phosphate enzymatically released from glucose-6-phosphate at $\mathrm{pH} 6.5$ according to Swanson (1955). The inorganic phosphate produced was determined as above.

Succinic dehydrogenase activity was measured by the enzymatic reduction of 2,6 dichlorophenolindophenol as described by Allen and Beard (1965).

\section{Enzyme Activity in Supernatants and Sediments}

Supernatant portions of lysosomal fractions were obtained by subjecting fractions to blending for 5 minutes at $4^{\circ} \mathrm{C}$ (Eberbach microattachment, Waring Blendor, $2 \mathrm{~cm}$ blade, $15,000 \mathrm{rev} / \mathrm{min}$ ), followed by centrifugation at $4^{\circ} \mathrm{C}$ in a Spinco Model $L$ centrifuge at $100,000 \times g$ for 60 minutes. The acid phosphatase activity associated with this supernatant was termed soluble acid phosphatase. Sediments derived after centrifugation were resuspended to starting volume with $0.25 \mathrm{M}$ sucrose. Acid phosphatase activity associated with the sediment was termed bound acid phosphatase. Bound enzyme was released into the soluble phase and rendered electrophoretically mobile in the presence of a $5 \%$ final concentration of Triton X-100 (Rohm and Haas). When biochemical or electrophoretic studies required bound enzyme free of soluble enzyme contamination, pellets were subjected to four cycles of washing with $0.25 \mathrm{M}$ sucrose or water, resuspension, and centrifugation at $100,000 \times g$ for 20 minutes before final resuspension to starting volume. Summed supernatant and sediment activities approached $100 \%$ of the activity of whole unseparated fractions. Physically solubilized enzyme accounted for $58 \%$ of the acid phosphatase activity of the lysosomal fraction, while $38 \%$ of the total activity was associated with the sediment. 


\section{Electrophoretic Separation of Enzymes}

Acrylamide electrophoresis. Electrophoretic separation of bound and soluble acid phosphatase in acrylamide gels was accomplished according to the method of Allen and Gockerman (1964). Localization of acid phosphatase in gels was achieved by incubating gels in a reaction mixture containing $0.005 \mathrm{M}$ sodium a-naphthyl acid phosphate and o-aminoazotoluene (Diazo Garnet GBC, Dajac), as described by Allen and Gockerman (1964). Gels were incubated at $25^{\circ} \mathrm{C}$. The reaction was stopped by replacement of the reaction mixture with $7.5 \%$ acetic acid. Densitometric measurement of dye deposited in the gels was accomplished with a scanning device attached to a Beckman DU spectrophotometer (Johnson \& Starkweather, 1962). Gels were scanned in $7.5 \%$ acetic acid. Optical density was measured at $545 \mathrm{~m} \mu$ using a Beckman potentiometric recorder. Deposition of enzymatically produced reaction product was linear with incubation time and enzyme concentration within the limits used for assay.

Small-scale preparative electrophoresis. A small-scale preparative electrophoretic system was constructed according to the specifications of Racusen and Calvanico (1964). Gel stocks and buffers were prepared exactly as for routine acrylamide electrophoresis (Allen \& Gockerman, 1964). Three $\mathrm{ml}(1 \mathrm{~cm}$ height) of lower gel solution was added to the separating chamber (1.8 cm I.D.). After polymerization, $6 \mathrm{ml}$ of a sample:sample gel mixture $(1: 2)$ was layered onto the separating gel. Polymerization was effected for 20 minutes with an ultraviolet light source. Eluates were collected from a plastic eluting chamber fitted with an inlet and outlet of polyethylene tubing (Intramedic, I.D. $.062^{\prime} \times$ O.D. .082'). Height of the eluting chamber was $1 / 8$ in., yielding a volume of $0.8 \mathrm{~cm}^{3}$. Electrophoresis was carried out for four hours at $300 \mathrm{v}$ starting potential. Fractions were collected for 5 minutes at a flow rate of $0.6 \mathrm{ml}$ eluate per minute using a Beckman Model 746 Solution Metering Pump and an automatic fraction collector. The fractions were assayed for acid phosphatase using a-naphthyl acid phosphate as substrate.

\section{RESULTS}

\section{Acrylamide Electrophoresis of Mitochondrial-Lysosomal Fractions}

The appearance of two electrophoretically distinguishable forms of acid phosphatase in mitochondrial-lysosomal fractions of rat liver (Allen \& Gockerman, 1964 ) was confirmed. When $20 \%$ fractions obtained by Scheme 1 were made $5 \%$ with Triton X-100 prior to electrophoresis, two bands of enzyme activity were detected, a fast-migrating component and a slow-migrating one. The slowmigrating component was detectable only after Triton treatment; the fast band was evident in untreated preparations. When mitochondrial-lysosomal fractions were blended, centrifuged for 30 minutes at $100,000 \times \mathbf{g}$, and the supernatant made $5 \%$ with Triton $\mathrm{X}-100$ prior to electrophoresis, only the fast-migrating band was evident. When the sediment was washed and made 5\% with Triton $\mathrm{X}-100$ prior to electrophoresis, only the slow-migrating component was visualized. The fast-migrating component was taken to represent soluble acid phosphatase released from mitochondrial-lysosomal fractions by physical disruption of particles. The slow-migrating component, appearing only after Triton treatment, was taken to represent the bound form of acid phosphatase.

\section{Separation of Two Forms of Acid Phosphatase Using Small-Scale Preparative Electrophoresis in Acrylamide Gels}

That two electrophoretically distinct forms of acid phosphatase are present in the mitochondrial-lysosomal fraction of rat liver was further demonstrated 
Sloat \& Allen: Lysosomal Acid Phosphatase
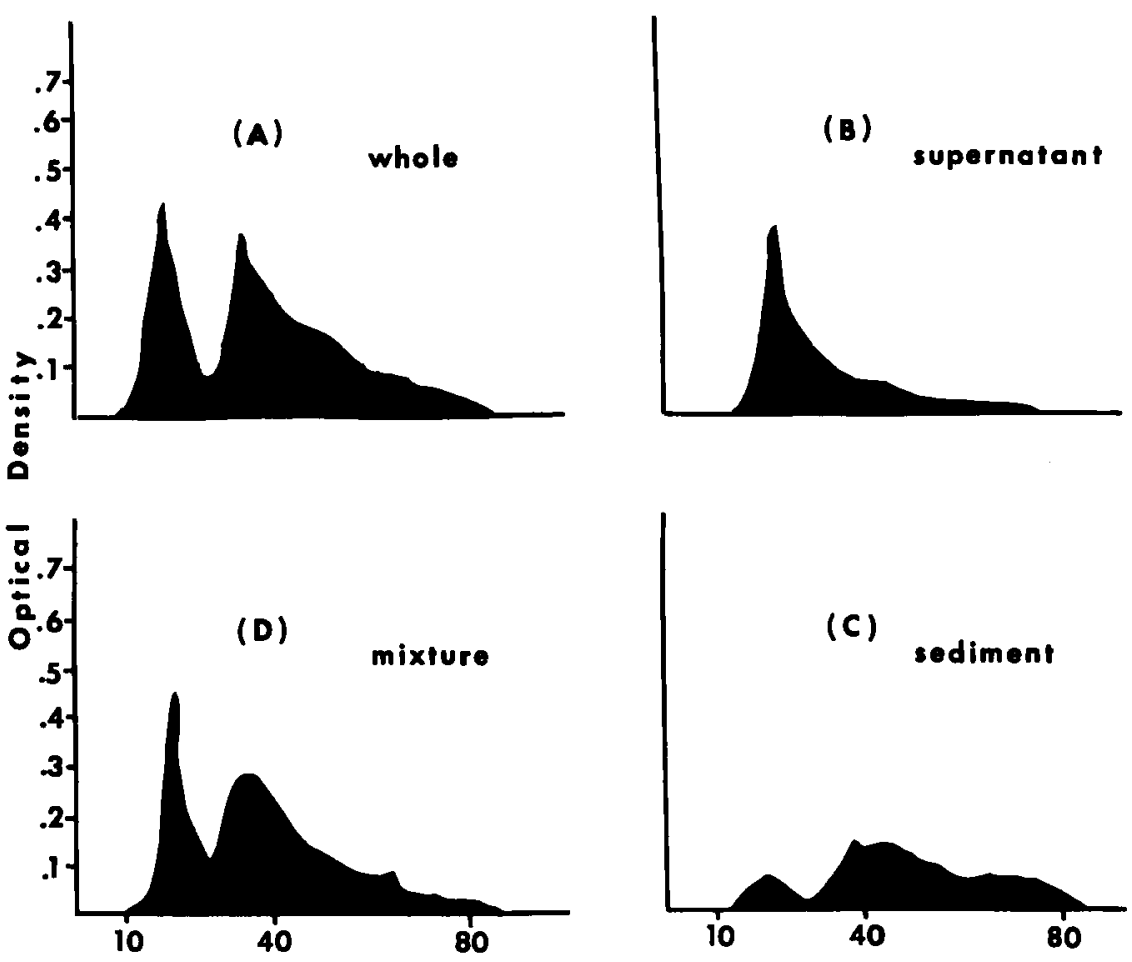

Tube Number

FIgURE 1. Preparative electrophoretic separation of soluble and bound acid phosphatase in $10 \%$ acrylamide gels. Mitochondrial-lysosomal fractions were derived according to differential centrifugation Scheme 1. Electrophoresis was accomplished as described in the text. Eluates were assayed using sodium $\alpha$-naphthyl acid phosphate as substrate. Two hundred $\mu$ l of eluate were assayed routinely, and incubation was for 30 minutes at $37^{\circ} \mathrm{C}$. (A) Whole fractions were made $5 \%$ with Triton $X-100$ and subjected to electrophoresis. Two elution peaks of activity were present. (B) Fractions were subjected to blending and centrifugation at $100,000 \times g$ for 30 minutes. Supernatants were made $5 \%$ with Triton $X-100$ before electrophoresis. One fastmigrating peak was evident. (C) Fraction sediments from (B) were resuspended and made $5 \%$ with Triton X-100. Electrophoresis followed, and one, slow-migrating, diffuse area of activity was detected. (D) Separated supernatants and sediments (B and C) were mixed prior to electrophoresis.

using small-scale preparative electrophoresis in acrylamide gels. Cell preparations were made $5 \%$ with Triton X-100. When mitochondrial-lysosomal fractions were subjected to electrophoresis, two elution peaks of acid phosphatase activity were detected (FIGURE 1, A). Soluble and bound fractions, when subjected to electrophoresis, resolved into one peak each, a fast-migrating one when soluble preparations were utilized (FIGURE 1, B), and a more slowly migrating, diffuse one (FIGURE 1, C) when preparations containing the bound form were subjected to electrophoresis. The elution peaks of separated supernatant and sediment portions of the mitochondrial-lysosomal fraction coincided in position with those of the whole fraction. The integrity of the separated forms was maintained when they were subjected to electrophoresis as a mixture (FIGURE 1 , D). When sodium $\beta$-glycerophosphate was employed as substrate, Triton $\mathrm{X}-100$ interfered with the formation of phosphomolybdenum blue. $N-N^{\prime}$-methy- 
lenebisacrylamide tetramethylethylene diamine (TEMED, Rohm and Haas) also interefered with the visualization process in the assay. Recovery of total enzyme activity, loaded onto gels before electrophoresis, was low; $30 \%$ when total eluate activity was compared to the activity of the starting sample.

\section{Biochemical and Physical Characterization of Separated Forms}

Sedimentation behavior. Ten percent mitochondrial-lysosomal fractions were made $5 \%$ with Triton X-100 to render all acid phosphatase soluble. These preparations were subjected to density gradient centrifugation in 5 to $20 \%$ sucrose-water gradients. After centrifugation, acid phosphatase activity was present as a single peak with a median position at a density of 1.032. When soluble acid phosphatase was osmotically released from the mitochondrial-lysosomal fraction by resuspension in distilled water and subjected to centrifugation as above, a single peak was found at a median position of density 1.031 . Repeated experiments with whole, soluble, bound and mixed preparations yielded the same, single peak of enzyme activity. The presence of both electrophoretic forms in peak activity gradient fractions derived from intact mitochondrial-lysosomal material, and of only the fast-migrating form in peak activity gradient fractions derived from soluble material, was confirmed by subjecting these fractions to acrylamide electrophoresis. Since no differences in the sedimentation behavior of the two forms were found, it is probable that the slower electrophoretic mobility of the bound form is not due to association of the enzyme with membranous components. When centrifugation time was extended to eight hours, similar preparations also yielded a single acid phosphatase activity peak.

$p H$. Whole, supernatant, and sediment preparations showed identical activity profiles in the range of $\mathrm{pH} 3.0$ to 6.5 when assayed in the presence of sodium $\alpha$-naphthyl acid phosphate, $p$-nitrophenyl phosphate or sodium $\beta$-glycerophosphate, although the forms of the profiles varied somewhat between substrates (FIGURE 2).

Inhibition studies. No differences in response to 2.5 to $20 \mathrm{mM}$ sodium tartrate, 2.5 to $20 \mathrm{mM}$ sodium fluoride, 0.1 to $1.3 \mathrm{M}$ formaldehyde, or 0.01 to $0.2 \mathrm{M}$ alloxan were noted among supernatant, sediment, and whole mitochondrial-lysosomal preparations when assayed in the presence of sodium $\alpha$-naphthyl acid phosphate, $p$-nitrophenyl phosphate, or sodium $\beta$-glycerophosphate. Activity could not be measured with sodium $\alpha$-naphthyl acid phosphate as substrate in the presence of alloxan due to its interference with color formation.

Heat inactivation. When whole, supernatant and sediment preparations, resuspended in $0.25 \mathrm{M}$ sucrose, were subjected to treatment at $50^{\circ} \mathrm{C}$ for 10,20 , 40 , and 80 minutes before enzyme assay, a striking difference in behavior was found between soluble and membrane-associated forms (FIGURE 3 ). Utilizing sodium $\alpha$-naphthyl acid phosphate (FIGURE 3, A), p-nitrophenyl phosphate (FIGURE 3, B), and sodium $\beta$-glycerophosphate (FIGURE 3, C) as substrates, the membrane-associated form showed no loss in activity after treatment at $50^{\circ} \mathrm{C}$ for 80 minutes, while $60 \%$ of the acid phosphatase activity of the soluble preparation was inhibited. Whole mitochondrial-lysosomal preparations showed an inactivation curve intermediate between soluble and bound curves. Identical results were obtained with or without Triton X-100 treatment of preparations, indicating that the heat stability of the bound form was not conferred by association of the enzyme with membraneous material. 


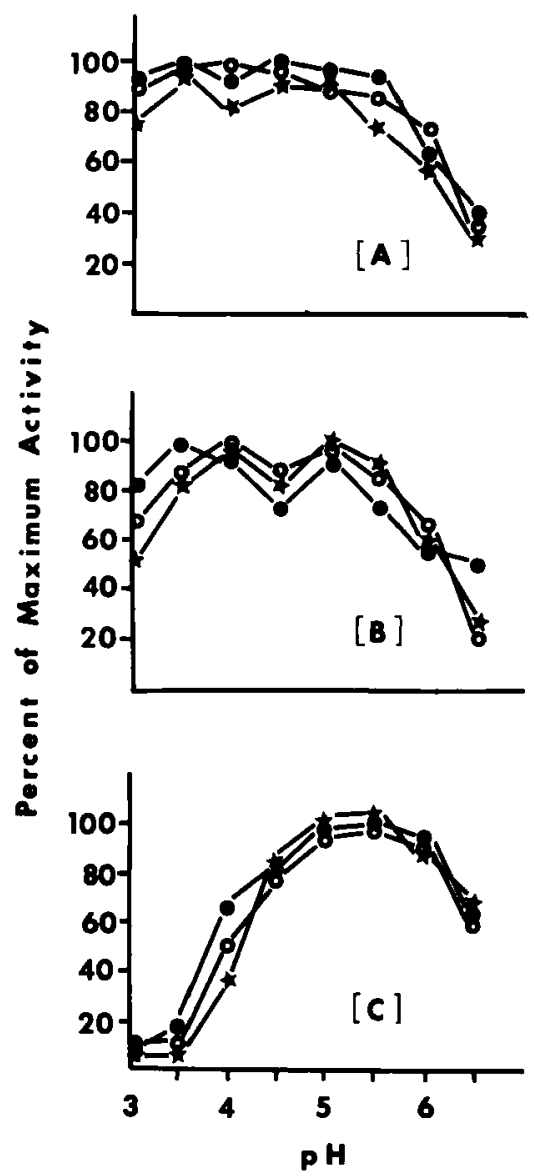

FIgURE 2. The pH optima for whole, supernatant, and sediment portions of mitochondriallysosomal fractions prepared according to differential centrifugation Scheme 1 and assayed in the presence of (A) p-nitrophenyl phosphate, (B) sodium $\beta$-glycerophosphate, and (C) sodium $a$-naphthyl acid phosphate. Fractions $(O)$ were blended and centrifuged at 100,000 $\times g$ for 30 minutes at $4^{\circ} \mathrm{C}$. Supernatants $\left({ }^{*}\right)$ were used for soluble activity. Sediments (O) were washed four times with water before final resuspension and use for bound enzyme activity. Activity is expressed as percent of activity at optimal $\mathrm{pH}$.

\section{Lysosomal Localization of Soluble and Bound Forms of Acid Phosphatase}

Differential centrifugation. Differential centrifugation distribution patterns (Scheme 2) for lysosomes, mitochondria, and microsomes were obtained using acid phosphatase, succinic dehydrogenase, and glucose-6-phosphatase, respectively, as marker enzymes (FIGURE 4). When calculated as percent of whole homogenate activity present in each fraction, 40 to $50 \%$ of the total acid phosphatase activity was recovered in the lysosomal fraction, with approximately $10 \%$ of the enzyme appearing in the soluble fraction. Sixty percent of the succinic dehydrogenase activity was recovered in the mitochondrial fraction; $60 \%$ of the glucose-6-phosphatase activity, in the microsomal fraction.

The distribution pattern for bound acid phosphatase alone (FIGURE 5, bottom), was obtained by subjecting differential centrifugation fractions (Scheme 2), made 
$5 \%$ in TX-100, to electrophoresis in acrylamide gels. The electrophoretic forms of acid phosphatase present in these fractions are shown in FIGURE 5 (top). No activity was detectable in the soluble fraction. Distribution of the bound enzyme was established by measuring the optical density of the slow-migrating band in the gels. A comparison of the bound enzyme pattern with that of the lysosomal and microsomal patterns of FIGURE 4 shows that the distribution of the bound enzyme follows that of the lysosomal population and not that of the microsomal one. It was noted, however, that while the major portion of bound enzyme appeared to reside in the lysosomal fraction, the enzyme did not follow exactly the lysosomal pattern obtained by differential centrifugation alone. A larger-than-expected amount of the bound form appeared to be associated with the microsomal fraction. Percent of total activity found in each fraction after differential centrifugation, and for bound enzyme after electrophoresis, is shown in TABLE 1.

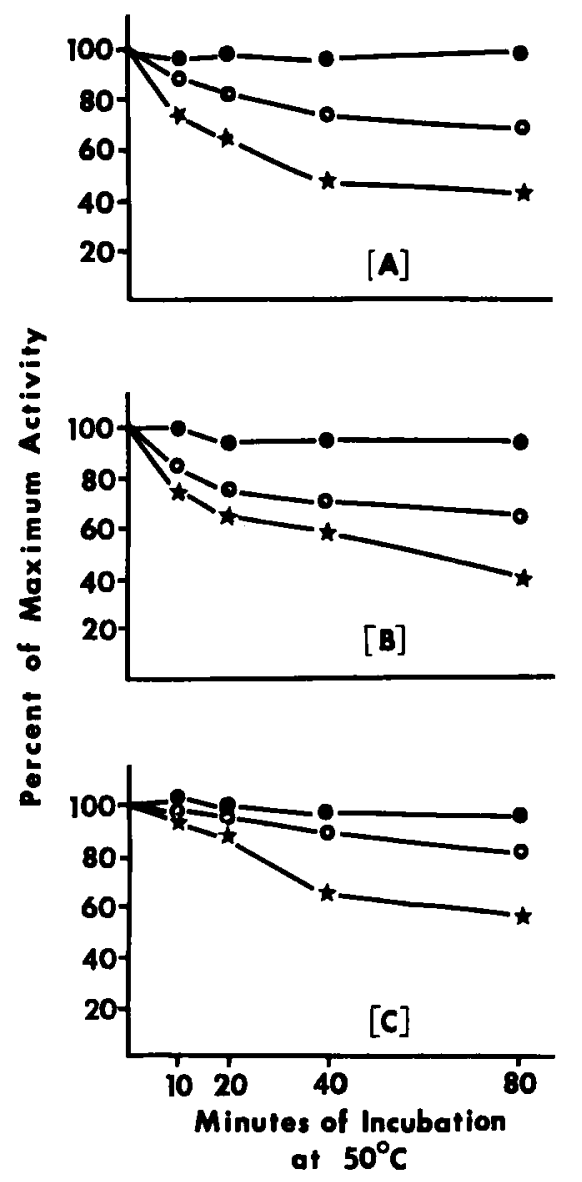

Figure 3. Heat inactivation of whole, soluble, and bound forms of acid phosphatase at $50^{\circ} \mathrm{C}$. Whole $(\mathrm{O})$, supernatant $(\star)$, and sediment $(O)$ portions of mitochondrial-lysosomal fractions were prepared as in Figure 2. Incubation at $50^{\circ} \mathrm{C}$ was for $10,20,40$, and 80 minutes prior to assay using (A) sodium $a$-naphthyl acid phosphate, (B) $p$-nitrophenyl phosphate, and (C) sodium $\beta$-glycerophosphate. Activity is expressed as percent of control, untreated activity. 


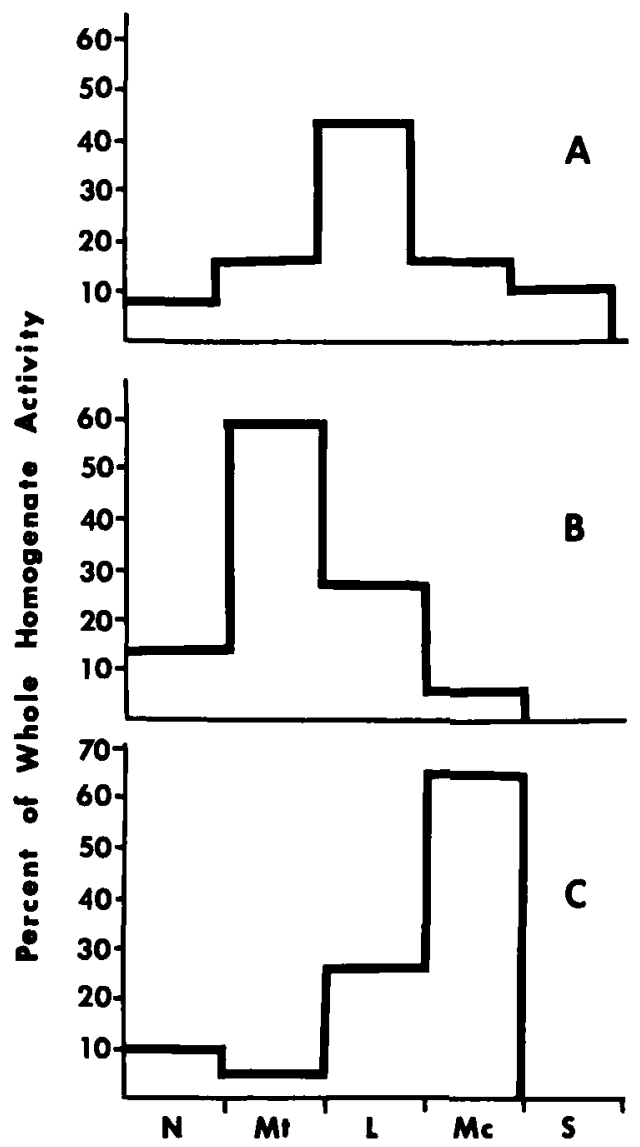

FIgURE 4. Distribution of (A) acid phosphatase, using sodium $a$-naphthyl acid phosphate as substrate; (B) succinic dehydrogenase; and (C) glucose-6-phosphatase after differential centrifugation (Scheme 2). $\mathbf{N}=$ nuclear; $\mathbf{M t}=$ mitochondrial; $\mathbf{L}=$ lysosomal; $\mathbf{M c}=$ microsomal; $\mathbf{S}=$ soluble.

Fourteen percent of the total acid phosphatase activity after differential centrifugation was attributed to the microsomal fraction, with $48 \%$ of the activity in the lysosomal fraction. However, $24 \%$ of the total bound enzyme activity was present in the microsomal fraction, with $41 \%$ localized in the lysosomal fraction.

Density gradient centrifugation. Density equilibrium centrifugation further established the lysosomal localization of both electrophoretic forms of acid phosphatase, and indicated a proportionately greater association of bound enzyme with "light" material. FigURE 6 illustrates the distinctly different distribution patterns for total acid phosphatase and for glucose-6-phosphatase when homogenates from which the nuclei had been removed were subjected to centrifugation. Median particle density for the lysosomal population was 1.200 ; for the microsomal population, 1.166. Distribution patterns for soluble and bound enzymes alone were obtained after electrophoresis of gradient fractions and subsequent photometric assay (FIGURE 7). Both enzyme forms clearly followed the lysosomal distribution as compared to the microsomal one. Proportionately larger 


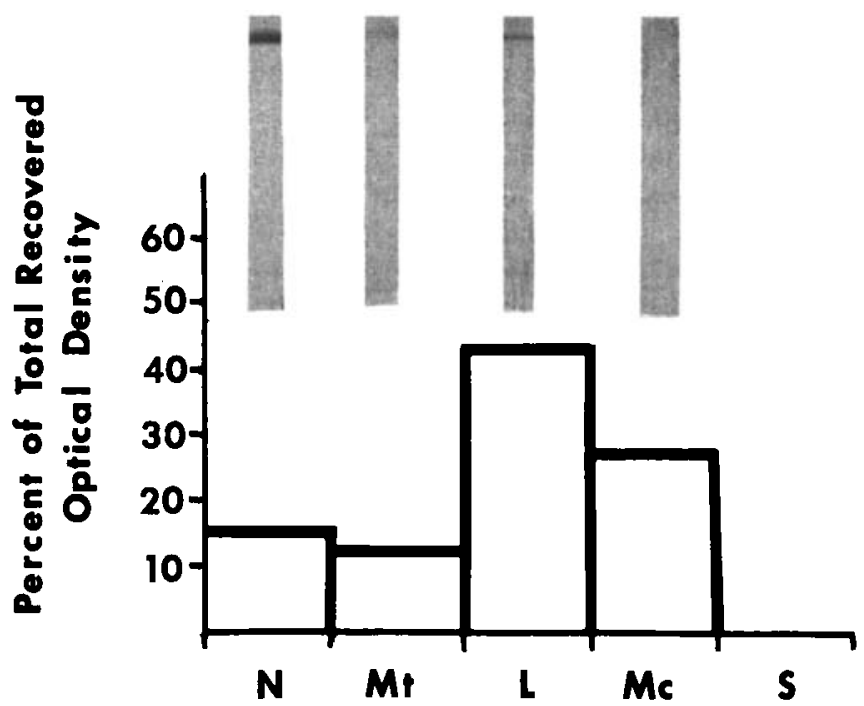

FIgURE 5. Distribution pattern (bottom of figure) of acid phosphatase in $10 \%$ acrylamide gels after electrophoresis of fractions obtained by differential centrifugation. Electrophoretic forms are shown at top of figure: $200 \mu$ l of sample:sample gel (1 part $20 \%$ fraction made $5 \%$ with Triton $X-100: 1$ part sample gel) was layered on lower gel; Incubation in a sodium $a$-naphthyl acid phosphate-Diazo Garnet GBC reaction mixture was at $25^{\circ} \mathrm{C}$ for 4 minutes. No activity was detected in the soluble fraction. Migration is toward the anode (bottom of figure). $\mathbf{N}=$ nuclear; $\mathrm{Mt}=$ mitochondrial; $\mathrm{L}=$ lysosomal; $\mathrm{Mc}=$ microsomal; $\mathbf{S}=$ soluble. Optical density of the slow-migrating component was measured by scanning gels with a modification of a Beckman DU spectrophotometer (Johnson \& Starkweather, 1962).

TABLE 1

Percent of Total activity in Fractions (scheme 2) Calculated for Total Acid Phosphatase and Bound Acid Phosphatase

\begin{tabular}{llcc}
\hline Fractions & $\begin{array}{c}\text { Total Acid Phosphatase } \\
\text { (Biochemical Assay) } \\
\text { \% Total Activity }\end{array}$ & $\begin{array}{c}\text { Bound Acid Phosphatase } \\
\text { (Photometric Scanning) } \\
\text { \% Total Activity }\end{array}$ \\
\hline Nuclear & 15 & 24 \\
Mitochondrial & 14 & 12 \\
Lysosomal & 48 & 41 \\
Microsomal & 14 & 24 \\
Soluble & 9 & - \\
\hline
\end{tabular}

amounts of the bound form in less dense regions of the gradient, however, suggested that a larger proportion of this form is associated with light components. That these components are lysosomal and not microsomal, is suggested by the close similarity of the bound enzyme pattern to that of the total lysosomal one, and its dissimilarity to the microsomal pattern.

A further distinction between the lysosomal and microsomal populations was established using velocity density gradient centrifugation in sucrose-water gradients. When homogenates were layered on these gradients, aggregation of particulate material occurred, with subsequent pelleting during centrifugation. This problem was circumvented by making gradients and homogenates $1.0 \mathrm{M}$ in $\mathrm{KCl}$ prior to centrifugation. When gradients were centrifuged for 20 minutes at 4,000 , 8,000 , and $16,000 \times g$, two distinct distribution patterns were obtained for acid 
phosphatase and glucose-6-phosphatase (FIGURE 8). Acid phosphatase-associated particles were observed to move further into the gradient with increasing gravitational forces. At $4,000 \times g$., the median position occupied by the lysosomal population was at a distance of $6.64 \mathrm{~cm}$ from the axis of rotation. At $8,000 \times \mathrm{g}$, the position was $7.15 \mathrm{~cm}$ from the axis; at $16,000 \times \mathrm{g} 8.18 \mathrm{~cm}$ from the axis of rotation. At $16,000 \times \mathrm{g}$, some lysosomes pelleted in the $2.0 \mathrm{M}$ sucrose cushion. Microsomes, on the other hand, remained at the top of the gradient under the same gravitational forces. At 4,000 $\times g, 8,000 \times g$, and $16,000 \times g$, the median position of the microsomal population was, respectively, $6.42,6.62$ and $6.64 \mathrm{~cm}$ from the axis of rotation. Thus, the distinction between the position of the lysosomal and microsomal populations was maintained to the extent that little overlap between the populations was found.

A determination of altered acid phosphatase distribution due to release of soluble enzyme in gradients containing $1.0 \mathrm{M} \mathrm{KCl}$ was made by pelleting all particulate material present in a lysosomal preparation made $1.0 \mathrm{M}$ with $\mathrm{KCl}$ (FIGURE 9). Centrifugation was at $124,000 \times g$ for 10 minutes. Material in the top fraction was designated solubilized acid phosphatase (unshaded), and accounted for $10 \%$ of the total acid phosphatase of the fraction. This value compared with that observed for solubilization in $0.25 \mathrm{M}$ sucrose without $\mathrm{KCl}$.

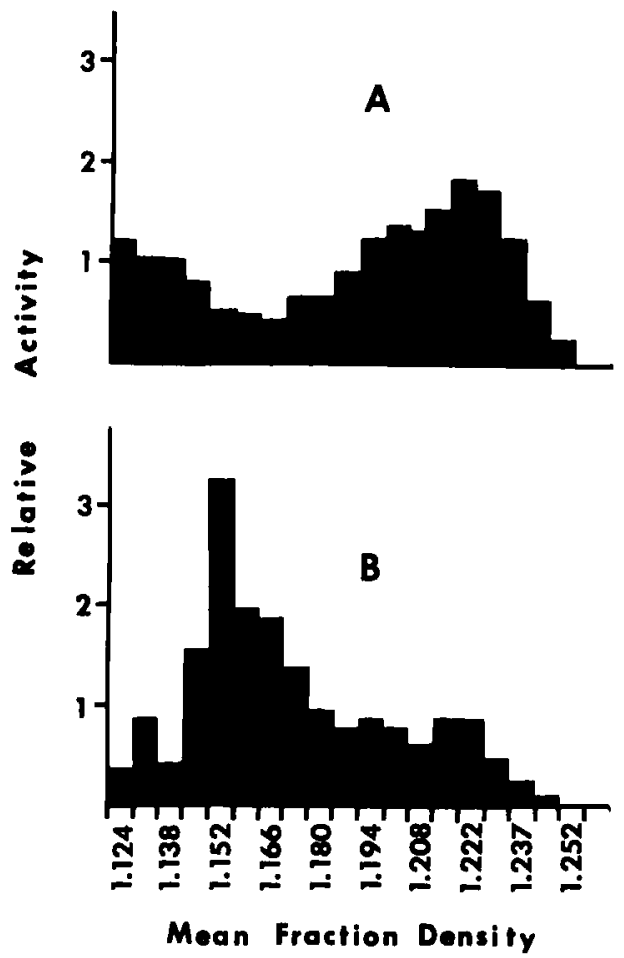

Figure 6. Distribution of (A) acid phosphatase, assayed using a-naphthyl acid phosphate as substrate; and (B) glucose-6-phosphatase after density gradient equilibrium centrifugation. Nuclei were removed from $20 \%$ homogenates by centrifugation at $480 \times g$ for 10 minutes prior to layering on gradients. For the gradient illustrated, median position of acid phosphatase was at a density of 1.205. Glucose-6-phosphatase median density was 1.168 . 


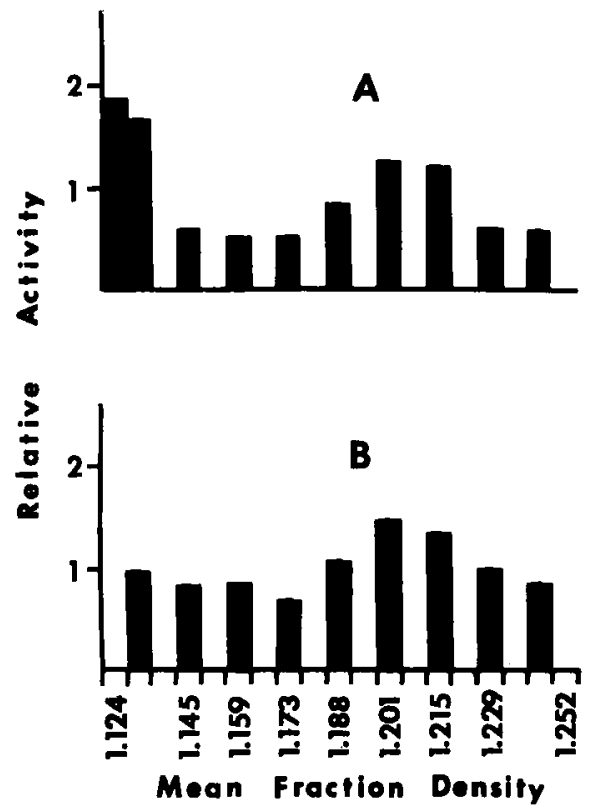

Figure 7. Distribution of (A) Soluble (fast-migrating band) and (B) Bound (slowmigrating band) acid phosphatase after density equilibrium centrifugation and electrophoresis in $10 \%$ acrylamide gels. Preparation was as in Figure 6. Gradient fractions were made 5\% with Triton X-100 prior to electrophoresis. Density of enzyme-produced dye deposited was determined by photometric scanning. Gels were incubated in sodium a-naphthyl acid phosphate:Diazo Garnet GBC reaction mixture for 4 minutes at $25^{\circ} \mathrm{C}$.

\section{Distribution of Acid phosphatase in Regenerating Liver}

Differential centrifugation. The suggestion from previous data that a higher proportion of the membrane-associated form of acid phosphatase is associated with slowly sedimenting lysosomes rather than with nonlysosomal material was further investigated using regenerating liver as experimental tissue. Tissue was examined at 24,48 , and 72 hours after partial hepatectomy. Liver removed at the time of the operation was used as control tissue. When such tissues were subjected to differential centrifugation according to Scheme 2, an altered distribution of acid phosphatase in regenerated liver as compared to control tissue was noted. This was manifested as an apparent increased proportion of the enzyme in the microsomal fraction (FIGURE 10). The portion of acid phosphatase activity recovered in the microsomal fraction increased from $16 \%$ in control tissue to $36 \%$ in 24 and 48-hour experimental tissue. At 72 hours after partial hepatectomy, fraction distributions again approached control levels. Liver tissue from animals partially hepatectomized 48 hours prior to sacrifice was chosen for further work.

Glucose-6-phosphatase assays were carried out to determine if alteration in the distribution of microsomal material had occurred in regenerating liver. Results of such analyses showed no differences in the distribution of microsomes between regenerating and control tissue (FIGURE 11). In both control and experimental tissue, $50 \%$ of the glucose-6-phosphatase activity was recovered in the microsomal fraction, and approximately $20 \%$ in the lysosomal fraction. 
These results suggested that the distributional shift of acid phosphatase in experimental animals was probably not related to an association of the enzyme with the endoplasmic reticulum, but to an altered character of the lysosomal population.

Velocity density gradient studies. To confirm an altered character of the lysosomal population, typified by more slowly sedimenting acid phosphataseassociated particles in regenerating liver, velocity density gradient analysis was undertaken. At $4,000 \times g$, a difference between the distribution profiles of particles in control and regenerated tissue was noted (FIGURE 12, A). Regenerating liver contained a greater proportion of slowly sedimenting lysosomes than did control liver. The median position occupied by the lysosomal population in control tissue was at a distance of $6.64 \mathrm{~cm}$ from the axis of rotation; in regenera-

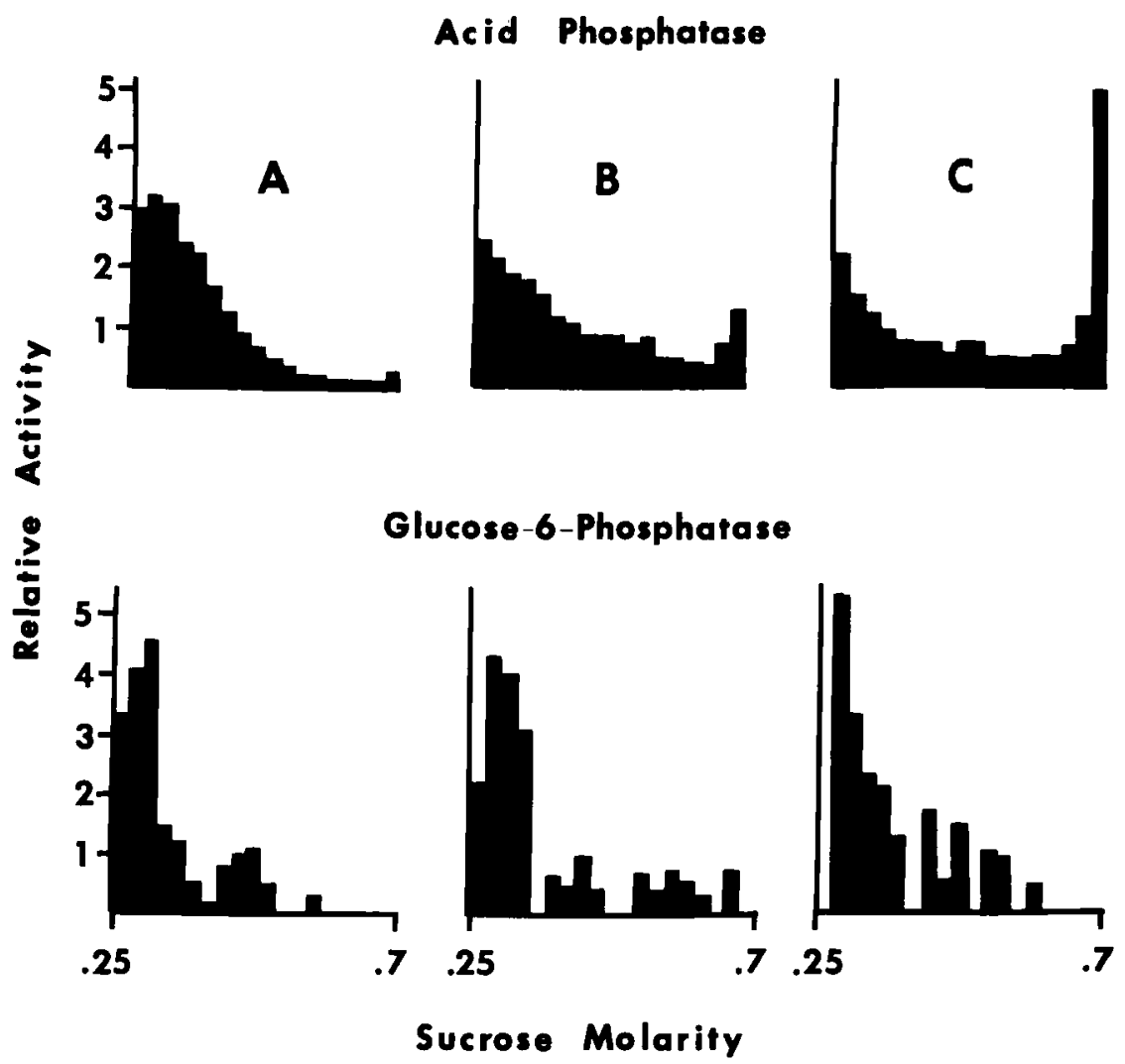

FIGURE 8. Distribution of acid phosphatase and glucose-6-phosphatase after velocity density gradient centrifugation at (A) 4,000 , (B) 8,000 and (C) $16,000 \times g$ for 20 minutes. Nuclei were removed from $20 \%$ homogenates by centrifugation at $270 \times g$ for 10 minutes followed by two resuspensions and recentrifugations at the same speed and time. Homogenates were made $0.2 \mathrm{M}$ with respect to sucrose and $1.0 \mathrm{M}$ with $\mathrm{KCl}$ before layering. Acid phosphatase was assayed using sodium $a$-naphthyl acid phosphate as substrate. The median position occupied by acid phosphatase at $4,000,8,000$ and $16,000 \times g$ for 20 minutes was $6.60,7.09$ and $8.19 \mathrm{~cm}$ from the axis of rotation for the experiment shown. For glucose-6-phosphatase under these conditions, median position occupied by the population was at a distance of $6.42,6.62$ and $6.64 \mathrm{~cm}$ from the axis of rotation. 


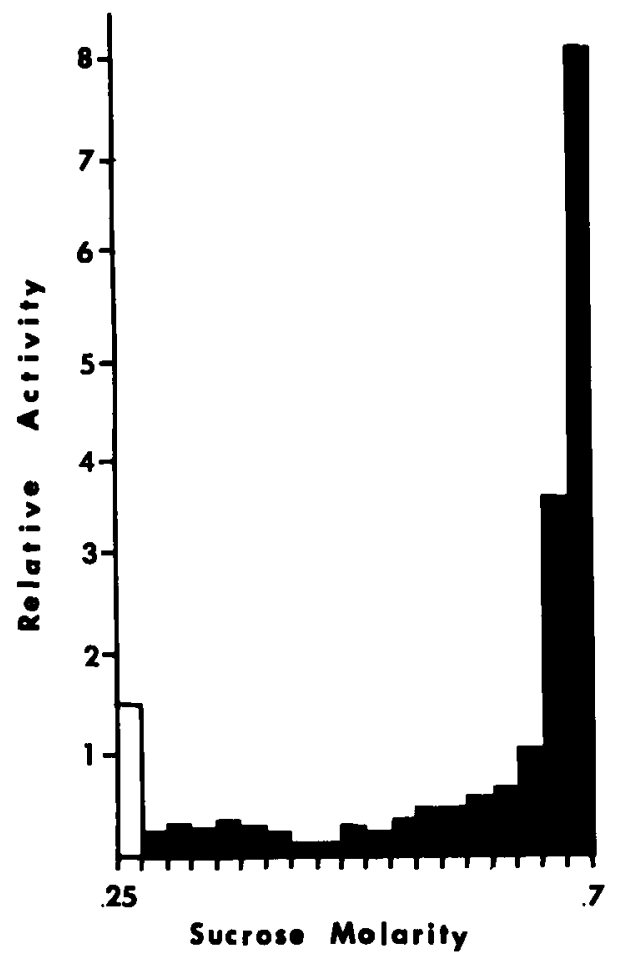

FIGURE 9. Separation of particulate and soluble acid phosphatase after velocity density gradient centrifugation at $124,000 \times g$ for 10 minutes. A lysosomal fraction was obtained from a $20 \%$ homogenate by differential centrifugation Scheme 2 . The fraction was made $4 \%$, $0.2 \mathrm{M}$ with respect to sucrose, and $1.0 \mathrm{M}$ with $\mathrm{KCl}$ prior to layering on gradients. Pelleted material was collected in a $2.0 \mathrm{M}$ sucrose cushion. Acid phosphatase was assayed using sodium $\alpha$-naphthyl acid phosphate as substrate.

ted tissue, the median distance was $6.48 \mathrm{~cm}$ from the axis. When gravitational forces were increased to $8,000 \times g$, the distributional differences were emphasized (FIGURE 12, B). Under these conditions, particles associated with acid phosphatase from control tissue were distributed more generally throughout the gradient. In regenerated tissue, however, a larger proportion of the acid phosphatase associated with particles remained in the lower density portions of the gradient. The median position of the population in the control tissue was 7.15 $\mathrm{cm}$ from the axis of rotation, while in regenerated tissue, the median position of the population was $6.68 \mathrm{~cm}$ from the axis. When control and experimental tissue was subjected to centrifugation at $124,000 \times g$ for 20 minutes to determine enzyme solubilization, particulate material from both experimental and control tissue pelleted (FIGURE 12, C). Solubilization in both tissues was comparable in all experiments, and ranged from 7 to $20 \%$ of the total acid phosphatase activity.

Concomitant acid phosphatase and glucose-6-phosphatase assays were carried out on regenerated liver after centrifugation for 20 minutes at 4,000, 8,000 and $16,000 \times g$ (FIGURE 13). Such experiments confirmed a difference in the distribution patterns between the lysosomal and microsomal populations as defined 


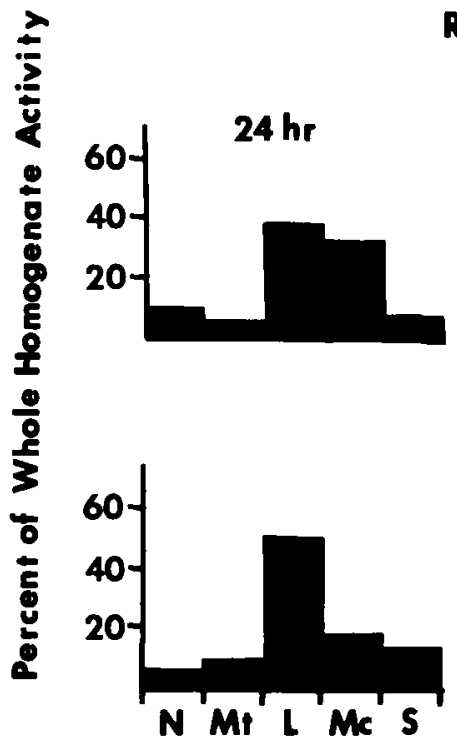

\section{Regenerated}
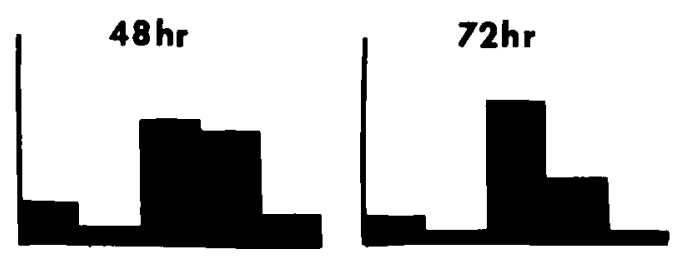

Control
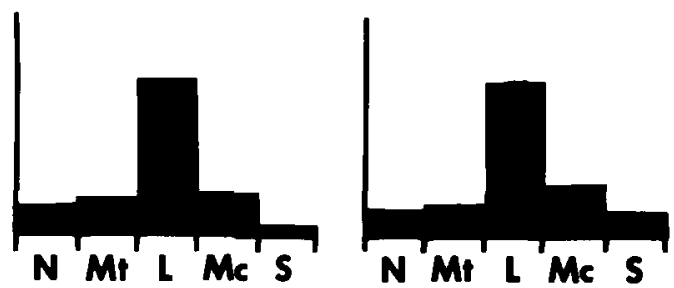

FIgURE 10. Distribution of acid phosphatase after differential centrifugation of control and regenerated liver at 24,48 and 72 hours after partial hepatectomy. Differential centrifugation was carried out according to Scheme $2, \mathrm{~N}=$ nuclear; $\mathrm{Mt}=$ mitochondrial; $\mathrm{L}=$ lysosomal; $\mathrm{Mc}=$ microsomal; $\mathbf{S}=$ soluble. Acid phosphatase was assayed using sodium $a$-naphthyl acid phosphate as substrate.

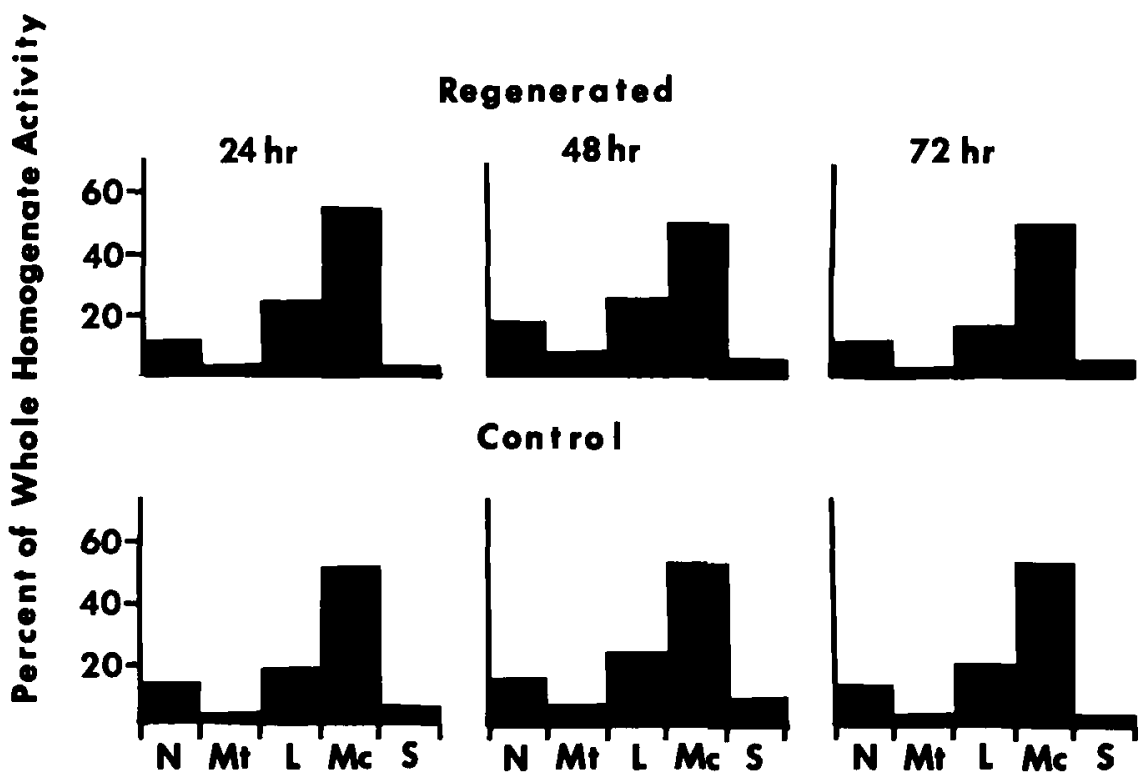

Figure 11. Distribution of glucose-6-phosphatase after differential centrifugation of control and regenerated liver at 24,48 and 72 hours after partial hepatectomy. Differential centrifugation was carried out according to Scheme 2 . $\mathbf{N}=$ nuclear; $\mathrm{Mt}=$ mitochondrial; $\mathrm{L}=$ lysosomal; $\mathbf{M c}=$ microsomal; $\mathbf{S}=$ soluble. 


\section{Regenerated}

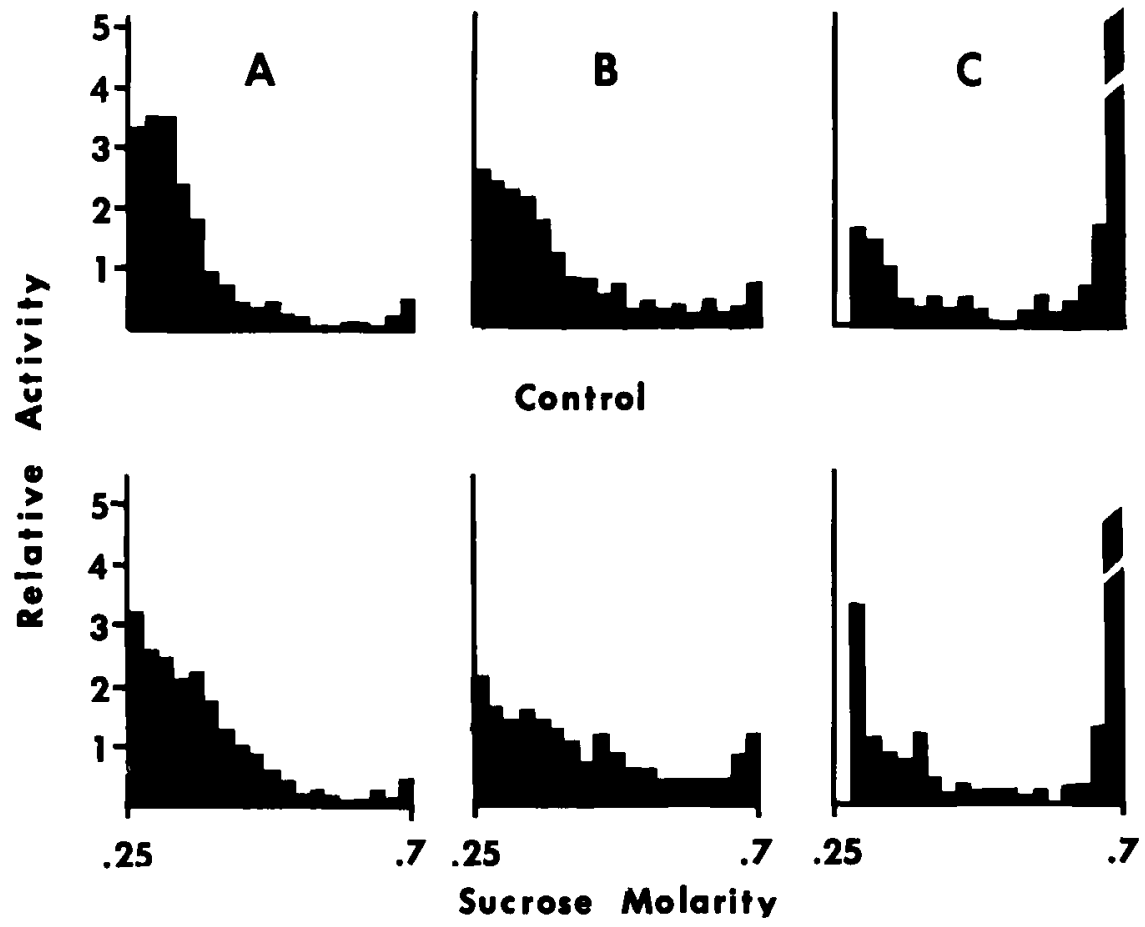

FIGURE 12. Distribution of acid phosphatase in regenerated and control liver $\mathbf{4 8}$ hours after partial hepatectomy following velocity density gradient centrifugation at (A) 4,000 , (B) 8,000 and (C) $124,000 \times g$ for 20 minutes. Nuclei were removed as in Figure 8. Homogenates were made $4 \%, 0.2 \mathrm{M}$ with respect to sucrose, and $1.0 \mathrm{M}$ with $\mathrm{KCl}$. Gradients contained $1.0 \mathrm{M}$ $\mathrm{KCl}$. Acid phosphatase was assayed using sodium $a$-naphthyl acid phosphate as substrate.

by the marker enzymes. Similar differences were demonstrated for control tissue (FIGURE 10). Regenerated liver showed a movement of acid phosphatase-associated particles with increasing gravitational forces from 6.48 to 6.68 to $7.94 \mathrm{~cm}$ from the axis of rotation. Microsomes, indexed by their glucose-6-phosphatase activity, remained in the light region of the gradient and were sedimented less rapidly at the gravitational forces described $(6.20$ to 6.39 to $6.64 \mathrm{~cm}$ from the axis of rotation). These determinations suggested that the acid phosphatase associated with slowly sedimenting material, a larger proportion of which appeared to be present in regenerating tissue, was not associated with membranes of the endoplasmic reticulum. Rather, they suggest that a shift in distribution due to increased numbers of lighter and hence more slowly sedimenting lysosomes occurred in regenerating liver. The median distance from the axis of rotation for the lysosomal and microsomal populations of experimental and control tissues is summarized in TABLE 2.

\section{Ratio of Soluble to Bound Acid Phosphatase in Control and Regenerating Tissue}

Supernatant-sediment analysis. Lysosomal and microsomal fractions derived from control and regenerated liver 48 hours after partial hepatectomy were 


\section{Acid Phosphatase}

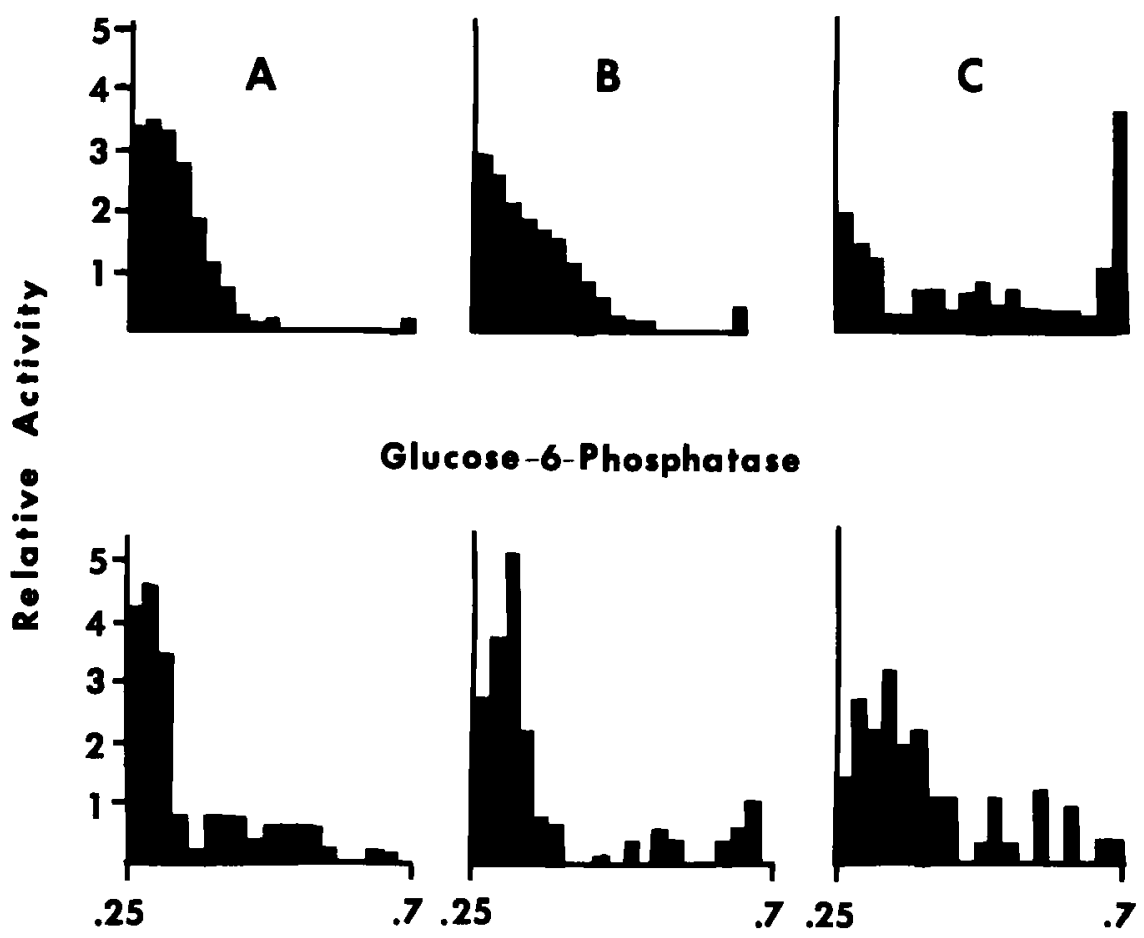

\section{Sucrose Molarity}

FIGURE 13. Distribution of acid phosphatase and glucose-6-phosphatase in liver 48 hours after partial hepatectomy following velocity density gradient centrifugation at (A) 4,000 $\times g$ for 20 minutes, (B) $8,000 \times g$ for 20 minutes and (C) $16,000 \times g$ for 20 minutes. Nuclei were removed as in FIGURE 8 . Homogenates were made $4 \%, 0.2 \mathrm{M}$ with respect to sucrose, and $1.0 \mathrm{M}$ with $\mathrm{KCl}$. Gradients contained $1.0 \mathrm{M} \mathrm{KCl}$. Acid phosphatase was assayed using sodium $a$-naphthyl acid phosphate as substrate. For the gradient illustrated, the median position occupied by acid phosphatase after centrifugation at $4,000,8,000$ and $16,000 \times 8$ for 20 minutes was at a distance of $6.40,6.62$ and $7.94 \mathrm{~cm}$ from the axis of rotation, respectively. Glucose-6-phosphatase under the same conditions was at a median distance of 6.20,6.39 and $6.64 \mathrm{~cm}$, respectively, from the axis of rotation.

\section{TABLE 2}

Median Distance From the Axis of Rotation of Acid Phosphatase and Glucose-6-Phosphatase in Control and Regenerated Liver 48 Hours After Partial Hepatectomy

\begin{tabular}{cccc}
\hline \hline & \multicolumn{2}{c}{ Median Position of Population in cm From the Axis of Rotation } \\
\cline { 2 - 4 } Assays & $\begin{array}{c}4000 \times g \\
20 \mathrm{Min}\end{array}$ & $\begin{array}{c}8000 \times g \\
20 \mathrm{Min}\end{array}$ & $\begin{array}{c}16,000 \times g \\
20 \mathrm{Min}\end{array}$ \\
\hline Acid Phosphatase & & & \\
Control Tissue & 6.64 & 7.15 & 8.18 \\
Regenerated Tissue & 6.48 & 6.68 & 7.94 \\
\hline Glucose-6-Phosphatase & & & 6.64 \\
Control Tissue & 6.42 & 6.62 & 6.64 \\
Regenerated Tissue & 6.20 & 6.39 & \\
\hline \hline
\end{tabular}


blended and centrifuged to yield a supernatant containing the soluble enzyme and a sediment containing the membrane-associated form. When the two preparations were made $5 \%$ with Triton X-100 and assayed for acid phosphatase activity using sodium $\alpha$-naphthyl acid phosphate as substrate, differences in the amount of acid phosphatase present in the supernatant and sediment portions of the fractions were found. Results were calculated as percent of the whole blended fraction recovered in the supernatant or sediment (TABLE 3). Analysis of microsomal fractions from control and regeneration tissue showed a higher proportion of bound enzyme in these fractions than in the lysosomal fraction from control tissue. However, the lysosomal fraction from regenerated tissue displayed a higher proportion of bound enzyme than did the control preparation for this

\section{TABLE 3}

Distribution of Acid Phosphatase in the Supernatant and Sediment Portions of Lysosomal and Microsomal Fractions (Scheme 2) of Control and Regenerated Liver 48 Hours After Partial Hepatectomy

\begin{tabular}{|c|c|c|c|c|}
\hline \multirow[b]{2}{*}{ Analysis } & \multicolumn{4}{|c|}{ Percent of Whole Blended Fraction } \\
\hline & Control & Regenerated & Control & Regenerated \\
\hline $\begin{array}{l}\text { Supernatant } \\
\text { Sediment }\end{array}$ & $\begin{array}{l}58 \\
45\end{array}$ & $\begin{array}{l}52 \\
53\end{array}$ & $\begin{array}{l}41 \\
55\end{array}$ & $\begin{array}{l}41 \\
52\end{array}$ \\
\hline
\end{tabular}

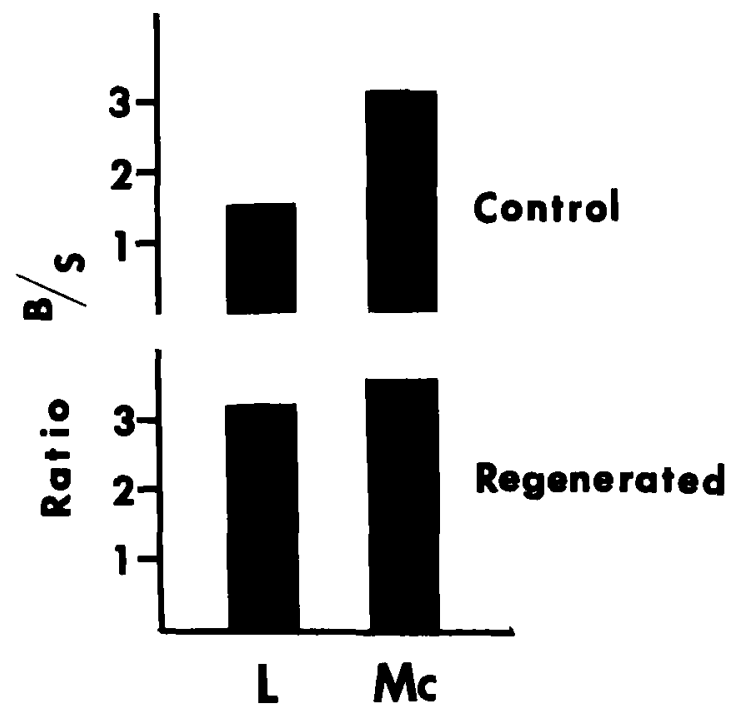

FIgURE 14. Ratio of bound (B) to soluble (S) acid phosphatase in lysosomal and microsomal fractions of control and regenerated liver after electrophoresis in $10 \%$ acrylamide gels. Lysosomal (L) and microsomal (Mc) fractions, obtained from animals partially hepatectomized 48 hours prior to sacrifice, and from control animals, were derived according to Scheme 2. Ten-percent fractions were made $5 \%$ with Triton $X-100$ and mixed with sample gel $(1: 1)$. Two hundred $\mu$ l of this mixture were layered onto polymerized lower gels. Electrophoresis was carried out for 90 minutes at $4^{\circ} \mathrm{C}$. Incubation at $25^{\circ} \mathrm{C}$ in sodium $a$-naphthyl acid phosphateDiazo Garnet GBC reaction mixture followed for 5 minutes, Optical density was measured by scanning gels as for Figure 5. Activity is expressed as the ratio of bound to soluble enzyme activity based on optical density of the dye deposit formed per unit time. 
fraction. Assuming, from previous data, that the acid phosphatase in both fractions is largely lysosomal, it appeared that slowly sedimenting lysosomes (microsomal fraction) showed a higher proportion of the membrane-associated form, and that the larger percentage of this form in the lysosomal fraction of regenerated liver was associated with new and more slowly sedimenting lysosomes in this fraction. Analysis of tissue from animals sacrificed 72 hours after partial hepatectomy gave similar results. At 24 hours after partial hepatectomy, an increase in the proportion of the membrane-associated enzyme in the microsomal fraction was noted, with no change in proportion apparent in the lysosomal fraction.

Electrophoresis. The above observations were extended using acrylamide electrophoresis of lysosomal and microsomal fractions. Figure 14 shows the relative proportions of bound to soluble enzyme in control and experimental tissue 48-hours after partial hepatectomy, as determined by densitometric measurement. A higher proportion of membrane-associated enzyme in the microsomal fraction was noted when compared to control tissue. After tissue regeneration for 48 hours, the proportion of membrane-associated to soluble enzyme in the lysosomal fraction increased from 1.5 to 3.3 ; in the microsomal fraction the change was from 3.0 in control to 3.7 in experimental tissue. Electrophoretic analysis of tissue obtained 24 hours after partial hepatectomy showed an increase in the proportion of the bound to soluble acid phosphatase in the lysosomal fraction from 1.5 in control tissue to 3.0 in experimental tissue. An increase from 3.0 to 4.5 was noted for the microsomal fraction. At 72 hours after partial hepatectomy, the proportion of bound to soluble acid phosphatase in both lysosomal and microsomal fractions increased, but the effect was complicated by a decreased detection of the soluble electrophoretic band.

The shift in proportion of bound to soluble enzyme between control and

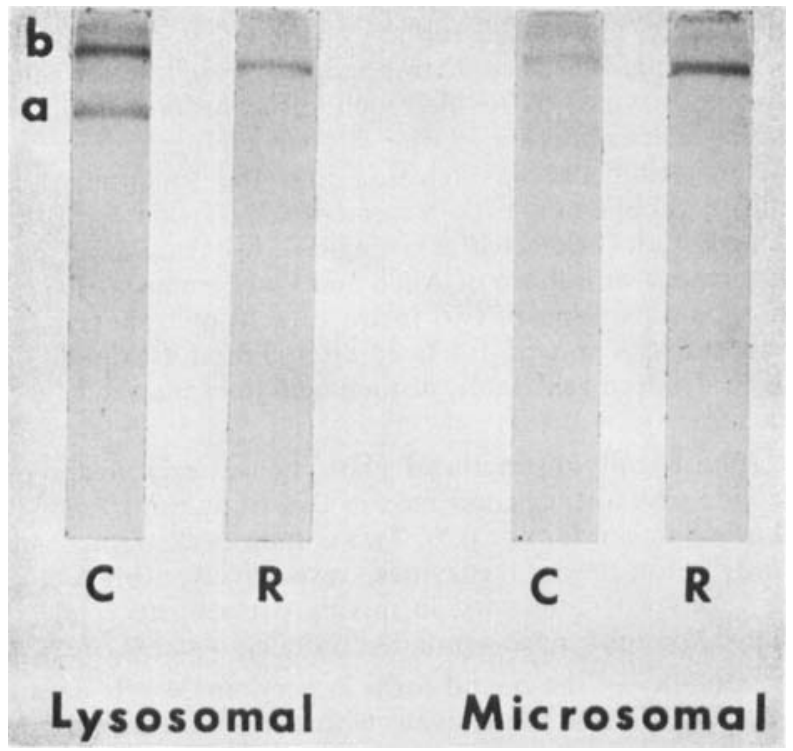

FIGURE 15. Distribution of acid phosphatase in $10 \%$ acrylamide matrices after electrophoresis of lysosomal and microsomal fractions of control (C) and regenerated (R) liver 48 hours following partial hepatectomy; (a) designates fast-migrating component (soluble enzyme), (b) slow-migrating component (bound enzyme). Preparations and electrophoresis as for FIGURE 14. Migration is toward the anode (bottom of figure). 
experimental tissue, derived 48 hours after partial hepatectomy, was readily apparent after visual examination of gels (FIGURE 15). Control lysosomal fractions showed the typical qualitative pattern, with slow- and fast-migrating components evident. Little of either band was evident in the microsomal fraction. Lysosomal fractions from regenerated liver showed a decrease in activity for both bands, with an increased proportion of the bound form. An increase in the activity of the bound form was evident in the microsomal fraction of this tissue.

\section{Discussion}

The multiple nature of rat liver acid phosphatases has been recognized for many years. Roche, in 1950, distinguished multiple forms of the enzyme on the basis of $\mathrm{pH}$ data and response to $\mathrm{Mg}^{++}$ions. Goodlad and Mills (1956; 1957) reported evidence for the existence of two or more forms of acid phosphatase in unfractionated rat liver, the forms exhibiting differential responses to $\mathrm{Mg}^{++}$ions, acetate and veronal buffers, and possessing different $\mathrm{pH}$ optima. Further, they exhibited different mobilities after electrophoresis in a Tiselius apparatus. No intracellular localization was established.

Barka in 1961 (Barka, 1961a) effected the separation of acid phosphatases of rat liver on polyacrylamide gels. He demonstrated three bands of activity, but obtained no evidence for differential substrate specificities at acid $\mathrm{pH}$. Chromatographically distinct acid phosphatases were separated by Moore and Angeletti (1961) and by Barka (1961b) from rat liver. Barka found four elution peaks of acid phosphatase activity, one of which was detectable only after treatment of homogenates with Triton X-100.

In this study, two electrophoretic forms of acid phosphatase were found in the lysosomal fraction. One of these was detectable only after Triton treatment. When assayed quantitatively, physical disruption of the fraction resulted in the release of only $60 \%$ of the total acid phosphatase activity of the fraction into the supernatant phase (soluble enzyme). After electrophoresis, this preparation displayed one rapidly migrating electrophoretic form. The remaining activity was associated with the fraction sediment, was released into the supernatant and rendered electrophoretically mobile only after treatment with Triton X-100. After electrophoresis, this activity was detected as a single, slowly migrating band. These results are in agreement with those of Allen and Gockerman (1964), who effected the electrophoretic separation of two forms of acid phosphatase from the mitochondrial-lysosomal fraction of rat liver after Triton treatment, and with the earlier finding of a Triton-releasable, distinct acid phosphatase in rat liver homogenates (Barka, 1961b).

That electrophoretically distinct acid phosphatases exist in the mitochondriallysosomal fraction was further confirmed in this study using small-scale preparative electrophoresis in acrylamide gels. Two elution peaks representing physically solubilized and Triton-released enzymes, respectively, were detected. The integrity of the forms was confirmed in mixing experiments, and no evidence of interconversion between them was found.

The slower mobility of the bound form in acrylamide gels does not appear to be due to an association of the enzyme with membraneous components. When soluble and Triton-released forms were subjected to sedimentation analysis in density gradients, no differences in sedimentation properties were noted between them. Had the bound form been associated with membrane material under these conditions, differences in sedimentation behavior would have been expected. 
The biochemical properties of the bound and soluble enzymes are similar. No differences between the forms were noted in response to sodium fluoride and sodium tartrate, as were reported for the multiple forms of rat liver acid phosphatase by Shibko and Tappel (1963) and Nelson (1966), and for guinea pig liver acid phosphatases by Neil and Horner (1964). The latter investigators also reported differential responses of lysosomal and soluble acid phosphatases to alloxan and formaldehyde. Differential responses to these inhibitors were not found for the enzymes reported here.

No differences in pH optima between the soluble and bound forms of the enzyme were detected. However, the nature of the $\mathrm{pH}$ optima curves varied somewhat among substrates. This behavior is consistent with earlier reports, and may form the basis for the reported multiple forms of rat liver acid phosphatase of other workers (Roche, 1950; Goodlad \& Mills, 1956; Nelson, 1966).

In 1966, Nelson implied the existence of both a heat-stable and a heat-labile form of acid phosphatase in rat liver lysosomal fractions. His report is consistent with the finding of this study that membrane-bound acid phosphatase, associated with the lysosomal fraction, is heat stable at $50^{\circ} \mathrm{C}$, while physically solubilized acid phosphatase loses up to $60 \%$ of its activity under such conditions. Differences in heat stability have also been detected for the acid phosphatases of plants (Williams \& Staples, 1964; Ikawa et al., 1964; Staples et al., 1965; Blum, 1965 ). It is unlikely that the heat stability of the bound form is conferred by an association of the enzyme with membranous components. Identical results were obtained whether or not the bound enzyme was heated while associated with the lysosomal sediment or after it was solubilized by Triton treatment. This difference in heat stability, coupled with the integrity exhibited by the electrophoretic forms after mixing experiments, suggests that the electrophoretic species are distinct enzymatic entities and are not artifacts of preparation or technique.

Quantitative studies of the distribution of acid phosphatase after differential centrifugation showed, as expected, a localization of the enzyme distinct from that of mitochondria and microsomes. Likewise, in a variety of density gradient sedimentations, the distribution of particles containing acid phosphatase was distinctly different from that of particles containing glucose-6-phosphatase. However, it was noted that an increased amount of acid phosphatase was associated with the microsomal fraction after differential centrifugation of liver homogenates from animals partially hepatectomized for 48 hours. Liver is a tissue in which synthesis of acid phosphatase (Walakinshaw \& Van Lancker, 1964) and acid phosphatase-associated particles (Bernhard \& Rouiller, 1956) occurs. However, this tissue did show a distribution of glucose-6-phosphatase identical to that found in control preparations. The identity of sedimentation behavior of particles containing glucose-6-phosphatase in both control and experimental tissues suggests that the increase in acid phosphatase in the microsomal fraction may not be due to an association between acid phosphatase and microsomes, but rather may represent an association of the enzyme with the newly developed, small, less dense lysosomes presumably present in regenerating tissue.

This point was further examined utilizing velocity density gradient centrifugation. Again it was found that the distribution profiles and the rate of sedimentation of particles containing acid phosphatase and those containing glucose-6phosphatase were distinctly different in both control and experimental tissues. In addition, these studies confirmed that a greater proportion of acid phosphatase is associated with more slowly sedimenting particles in homogenates derived from regenerated liver. 
Electrophoretic evidence confirmed the lysosomal localization of both forms of acid phosphatase by showing the major portion of each to be associated with the lysosomal fractions derived from both control and regenerated liver. It was found, however, that after electrophoresis of fractions obtained by differential centrifugation, the distribution of bound acid phosphatase differed from that of the soluble enzyme. A greater-than-expected proportion of the membrane-bound component was present in the microsomal fraction. This effect was particularly pronounced in preparations derived from regenerated liver. Comparison of the pattern of bound enzyme distribution with that of glucose-6-phosphatase, however, again suggested a lysosomal localization of the enzyme rather than an association with the endoplasmic reticulum, since, as noted above, the distribution of the latter enzyme was identical in control and experimental samples. Electrophoretic analysis of the distribution of the bound and soluble forms of acid phosphatase after density equilibrium centrifugation likewise suggested that both forms of the enzyme are associated with lysosomal rather than with microsomal material. This type of analysis again indicated that a proportionately greater amount of the bound enzyme was associated with particles occupying less dense regions of the gradients.

The above interpretation is based upon the assumption that acid phosphatase and glucose-6-phosphatase are valid markers reflecting the existence of two distinct subcellular populations. That the microsomal population reflects endoplasmic reticulum membranes vesiculated during fractionation procedures, was established by the biochemical and electron microscopic study of Palade and Siekevitz in 1956. Glucose-6-phosphatase is exclusively a microsomal enzyme (Swanson, 1955) and the one generally employed as marker enzyme for the population. In electron micrographic cytochemical studies, all sections of the endoplasmic reticulum are reported to contain the enzyme (Orrenhius \& Ericsson, 1966). Acid phosphatase, on the other hand, is the classical marker for lysosomes, with little or no reaction product found associated with the endoplasmic reticulum (Novikoff et al., 1964; Novikoff, 1961).

The localization of some acid phosphatase in the endoplasmic reticulum has been suggested for rat and mouse liver by Fishman, et al. (1967), and for rat liver, especially after regeneration, by Walkinshaw and Van Lancker (1964). The presence of acid phosphatase, or any enzyme, in the endoplasmic reticulum is consistent with the fact that most enzyme synthesis occurs there, and a transient localization of enzymes in the endoplasmic reticulum is implicit in the theory of zymogen granule formation and storage established by Caro and Palade (1964). Thus, while the lysosomal and microsomal populations are clearly distinct, at any one time both acid phosphatase and glucose-6-phosphatase may, in fact, be present simultaneously in particles where these populations overlap in sedimentation behavior, making total distinction between them impossible. In spite of this region of uncertainty, the above data suggest that the preponderance of bound acid phosphatase resides in the lysosomal population and not in the endoplasmic reticulum.

The prevalent theory of lysosome formation implicates the Golgi apparatus in the formation of primary lysosomes as Golgi vesicles (Novikoff et al., 1964). As suggested by the theory of zymogen granule formation (Caro \& Palade, 1964), acid hydrolases may travel through channels of the endoplasmic reticulum to the Golgi apparatus where they are subsequently packaged as vesicles. This theory is supported by the evidence of Bainton and Farquhar (1966) that granules of rabbit leukocytes are primary lysosomes (de Duve, 1963; Hirsch \& Cohn, 
1964), and that they form from the Golgi apparatus. The existence of membranebound lysosomal acid phosphatase is not readily accounted for by this theory, however, since the transport form of the enzyme would be expected to be soluble or at least not part of the membrane components of the particle.

If, as seems likely on the basis of the data presented here, the bound acid phosphatase of lysosomes is associated with lysosomal membranes, they are likely to be derived from either the membrane of the Golgi vesicles or from the membranes of the endoplasmic reticulum. The existence of bound acid phosphatase in these cellular membranes is consistent with the theory that such membranes may be a mosaic of functionally different patches (Korn, 1966) that have been simultaneously assembled from their component lipids, structural proteins and enzymatic proteins (Dallner, et al. 1966). Development of lysosomes directly from membranes of the endoplasmic reticulum has been suggested for protozoa (Elliott, 1965), rat kidney (Ericsson, 1964) and rat liver (Novikoff \& Shin, 1964). Similarly autophagic vesicles appear to develop directly from endoplasmic reticulum sites (Van Lancker, 1964; Ashford \& Porter, 1962; Ericsson, 1964; de Duve \& Wattiaux, 1966 Deter \& de Duve, 1967; Deter et al., 1967). Thus, lysosomes may originate as small, membrane-bound vesicles with structural hydrolases composing an integral part of the membrane.

Whether small lysosomes containing more membrane-bound enzyme represent a developmental sequence from primary lysosomes to older, secondary particles cannot be unequivocally answered, although data derived from regenerating tissue support the suggestion. Deter and de Duve (1967) indicated such a possibility in their report of the existence of a population of small dense bodies after glucagon treatment and their implication of an enlargement of the particles with the development of autophagic vacuoles. Such a sequence also seems consistent with the general evolutionary sequence suggested by de Duve and Wattiaux (1966), in which lysosomes in early cells were represented by vacuolar sections of the endoplasmic reticulum, which contained hydrolases.

The nature of the binding of acid phosphatase to the lysosomal membrane is unknown. That it is very firm is indicated by the failure of strenuous physical treatment to remove it. Extraction with acetone and carbon tetrachloride effected no solubilization of the component (Allen \& Gockerman, 1964). It was, however, readily extracted by them with digitonin, Triton X-100, and to some extent with butanol, treatments which disperse lipoprotein complexes (Morton, 1955). That such complexes may occur at the lysosomal membrane or within the particles, has been suggested by Koenig (1962). According to his theory, release may involve cleavage of glycoprotein, enzyme bonds, making enzyme accessible to substrate. Sawant et al. (1964a) implicated electron binding as a factor in the attachment of acid phosphatase, $\boldsymbol{\beta}$-glucuronidase, cathepsin and aryl sulfatase to lysosomal membranes. Bound acid phosphatase has been reported by Shibko and Tappel (1963) and Sawant et al. (1964b). These workers reported that $30 \%$ or more of the acid phosphatase remains in the sedimentable phase after physical treatments. Shibko and Tappel (1963) found a membrane-bound esterase; Ugazio and Pani (1963), aryl sulfatase a; Beck and Tappel (1968), $\beta$-glucosidase; and Weissman et al. (1967), $\beta$-acetylglyucosaminidase, all in rat lysosome fractions. In terms of lysosomal function, such enzymes may be implicated in a postulated two-stage release of hydrolases (Shibko et al., 1964; Beck \& Tappel, 1968), in one step of which enzyme becomes accessible to substrate, but remains sedimentable, and in the next step becoming soluble and unsedimentable. The mechanism of 
release of bound acid phosphatase from membranes to an actively hydrolytic role as a soluble enzyme is open to question.

\section{SUMMARY}

Two varieties of acid phosphatase associated with lysosomal fractions derived from rat liver have been identified after electrophoresis in acrylamide gels. One form is a rapidly migrating enzyme released after physical disruption of lysosomal fractions. The other form is electrophoretically mobile only after treatment of Iysosomal fractions with $5 \%$ Triton X-100. This enzyme appears to be associated with lysosomal membranes and accounts for approximately $40 \%$ of the total acid phosphatase of the lysosomal fraction.

The membrane-associated and soluble forms identified electrophoretically have been individually isolated by a preparative electrophoretic technique. The integrity of these forms is maintained when they are subjected to reelectrophoresis singly or as mixtures. The soluble enzyme and Triton-solublized bound enzyme show identical activity profiles when subjected to density equilibrium centrifugation in sucrose : water gradients, suggesting that the bound form is no longer associated with membraneous components. Biochemical assays of fractions derived by differential and density gradient centrifugation combined with photometric assay after electrophoresis indicated that both soluble and membrane-bound forms are associated with the lysosomal population.

Lysosomal fractions, disrupted by blending, were centrifuged to yield a supernatant fraction containing the soluble enzymes and a sediment containing the membrane-associated form. Biochemical studies of these preparations indicated that the membrane-associated acid phosphatase is heat stable $\left(50^{\circ} \mathrm{C}\right.$ for 80 minutes) in contrast to the soluble enzyme, which lost $70 \%$ of its activity under these conditions. Bound and soluble enzymes possess a similar $\mathrm{pH}$ optimum and respond to inhibition by $\mathrm{L}$-tartrate, fluoride, alloxan and formaldehyde in the same manner.

Studies of regenerating and control liver were undertaken at 24, 48 and 72 hours after partial hepatectomy. A distributional shift of acid phosphatase toward an association with lighter particles was noted after differential and density gradient centrifugation. Such a shift appears to be related to a change in the characteristics of the lysosomal population rather than to any association with the elements of the endoplasmic reticulum. Biochemical and electrophoretic data indicated that lysosomal fractions derived from regenerating liver contain a larger proportion of bound to soluble enzyme than fractions from control animals. Such data suggest that a proportionately larger amount of bound enzyme may be associated with a more slowly sedimenting and presumably smaller population of lysosomes.

\section{REFERENCES}

ALLEN, J. M. \& M. E. BeArD. 1965. L-Hydroxy acid oxidase: Localization in renal microbodies. Science 149: 1507-1509.

ALlen, J. M. \& J. Gockerman. 1964. Electrophoretic separation of multiple forms of particle associated acid phosphatase. Ann. N. Y. Acad. Sci. 121 : 616-633.

APPelmans, F. \& C. DEDuvE. 1958. Tissue fractionation studies. 3. Further observations on the binding of acid phosphatase by rat-liver particles. Biochem. J. 59: 426-433.

AshFord, T. P. \& K. R. PorTer. 1962. Cytoplasmic components in hepatic cell lysosomes. J. Cell Biol. 12: 198-202.

Bainton, D. F. \& M. G. Farquhar. 1966. Origin of granules in polymorphonuclear leukocytes. Two types derived from opposite faces of the Golgi complex in developing granulocytes. J. Cell Biol. 28: 277-301. 
BARKa, T. 1961a. Studies of acid phosphatase. I. Electrophoretic separation of acid phosphatases of rat liver on polyacrylamide gels. J. Histochem. Cytochem. 9: 542-547.

BARKA, T. 1961b. Studies of acid phosphatase. II. Chromatographic separation of acid phosphat ases of rat liver. J. Histochem. Cytochem. 9: 564-571.

Beaufay, H., P. Jacques, P. Baudhuin, O. Sellinger, J. Berthet \& C. DeDuve. 1964. Resolution of mitochondrial fractions from rat liver into three distinct populations of cytoplasmic particles by means of density equilibration in various gradients. Biochem. J. 92: 184-205.

Beck, C. \& A. L. TAPpel. 1968. Rat liver lysosomal B-glucosidase; a membrane enzyme. Biochim. Biophys. Acta 151: 159-164.

Bernhard, W. \& C. Roulller. 1956. Close topographical relationship between mitochondria and ergastoplasm of liver cells in a definite phase of cellular activity. J. Biophys. Biochem. Cytol. Suppl. to 2: 73-77.

Berthet, J., L. Berthet, F. Appelmans \& C. DeDuve. 1951. Tissue fractionation studies. 2. The nature of the linkage between acid phosphatase and mitochondria in rat liver tissue. Biochem. J. 50: 182-189.

Blum, J. J. 1965. Observations of acid phosphatases of Euglena gracilis. J. Cell Biol. 24: 223-234.

Caro, L. G. \& G. E. Palade. 1964. Protein synthesis, storage, and discharge in the pancreatic exocrine cell. J. Cell Biol. $20: 473-495$.

Daems, W. T. \& T. G. VAN Russer. 1961. The fine structure of the peribiliary dense bodies in mouse liver tissue. J. Ultrastruct. Res. 5: 263-290.

Dallner, G., P. Siekevitz \& G. Palade. 1966. Biogenesis of ER membranes. II. Synthesis of constitutive microsomal enzymes in developing rat hepatocytes. J. Cell Biol. 30: 97-117.

DE DUve, C. 1959. Lysosomes, a new group of cytoplasmic particles. In Subcellular Particles. T. Hayashi, Ed. : 128-159. Ronald Press, N. Y.

DE DUVE, C. 1963. The lysosome concept. In Ciba Foundation Symposium on Lysosomes. A. V. S. Reuck \& M. P. Cameron, Eds. : 1-31. Little, Brown \& Co., Boston, Mass.

DE Duve, C. \& R. Wattiaux. 1966. Functions of lysosomes. Ann. Rev. Physiol. 28: 435492.

Deter, R. L., P. BAudhuin \& C. DE Duve. 1967. Participation of lysosomes in cellular autophagy induced in rat liver by glucagon. J. Cell Biol. 35: C11-C16.

DETER, R. L. \& C. DE Duve. 1967. Influence of glucagon, an inducer of cellular autophagy, on some physical properties of rat liver lysosomes. J. Cell Biol. 33: 437-449.

Dryer, R. L., A. R. TAmmes \& J. I. Routh. 1957. The determination of phosphorus and phosphatase with N-phenyl-p-phenylenediamine. J. Biol. Chem. 225: 177-183.

ElL10TT, A. M. 1965. Primary lysosomes in Tetrahymena pyriformis, Science 149: 640-641.

Ericsson, J. L. E. 1964. Absorption and decomposition of homologous hemoglobins in renal proximal tubular cells. Acta Path. Microbiol. Scand. Suppl. to 168: 1-121.

Fishman, W. H., S. S. Goldman \& D. DeLellis. 1967. Dual localization of $\beta$-glucurodinase in endoplasmic reticulum and in lysosomes. Nature (London) 213: 457-460.

Goodlad, G. A. J. \& G. T. Mills. 1956. The multiple nature of rat liver acid phosphatase activity. Biochem. J. 63: 14.

Goodlad, G. A. J. \& G. T. Mills. 1957. The acid phosphatases of rat liver. Biochem. J. 66: 346-354.

Higgins, G. M. \& R. M. Anderson. 1931. Experimental pathology of the liver. I. Restoration of the liver of the white rat following partial surgical removal. Arch. Path. (Chicago) 12: 186-202.

Hirsch, J. G. \& Z. A. CoHN. 1964. Digestive and autolytic function of lysosomes in phagocytic cells. Fed. Proc. 23: 1023-1025.

Hogeboom, G. H. \& E. L. KufF. 1954. Sedimentation behavior of protein and other materials in a horizontal preparative rotor. J. Biol. Chem. 210: 733-751.

IKaWA, T., K. Nisizawa \& M. TOMOE. 1964. Specificities of several acid phosphatases from plant sources. Nature (London) 203: 939-940.

Johnson, J. D. \& W. StaRKWEather. 1962. A simple, improved microdensitometric recording method for slide mounted electrophoretic systems. Proceedings of the Tenth Annual Detroit Conference, Assoc. Anal. Chemists (Paper No. 15).

KoENIG, H. 1962. Histological distribution of brain gangliosides; lysosomes as glycolipoprotein granules. Nature (London) 195: 782-784.

KoRN, E. D. 1966. Structure of biological membranes. Science (London) 153: 1491-1498.

MARTIN, R. G. \& B. N. AMES. 1961. A method for determining the sedimentation behavior of enzymes: application to protein mixtures. J. Biol. Chem. 236: 1372-1379.

MOORE, B. W. \& P. U. ANGeletTI. 1961. Chromatographic heterogeneity of some enzymes in normal tissues and tumors. Ann. N. Y. Acad. Sci. 94; 659-667. 
MORTON, R. K. 1955. Methods of extraction of enzymes from animal tissues. In Methods in Enzymology. S. Colowick \& N. Kaplan, Eds., I; 25-51. Academic Press, Inc., New York, N. Y.

Neil, M. W. \& M. W. Horner. 1964. Studies on acid hydrolases in adult and foetal tissues. Acid phosphatase p-nitrophenyl-phosphate phosphehydrolases of adult Guineapig liver. Biochem. J. 92: 217-224.

Nelson, B. D. 1966. Rat liver acid phosphatase: differences in lysosomal and cytoplasmic forms. Proc. Soc. Exp. Biol. Med. 121: 998-1001.

Novikoff, A. B. 1961. In The Cell. J. Brachet \& A. E. Mirsky, Eds., II: 423-488. Academic Press, Inc., New York, N. Y.

Novikoff, A. B., Beaupay, H. \& C. DE Duve. 1956. Lysosome rich fractions from rat liver. J. Biophys. Biochem. Cytol. 2: 179-184.

Novikoff, A. B., Essner, E. \& N. Quintana. 1964. Golgi apparatus and lysosomes. Fed. Proc. 23: 1010-1022.

Novikoff, A. B. \& W. Y. SHIN. 1964. The endoplasmic reticulum in the Golgi zone and its relations to microbodies, Golgi apparatus, and autophagic vacuoles in rat liver cells. $J$. Mikroskopie 3: 187-206.

OrRenhtus, S. \& J. L. E. Ericsson. 1966. On the relationship of liver glucose-6-phosphatase to the proliferation of endoplasmic reticulum in phenobarbital induction. J. Cell Biol. 31 : 243-256.

Palade, G. E. \& P. Siekevitz. 1956. Liver microsomes. An integrated morphological and biochemical study. J. Biophys. Biochem. Cytol. 2: 171-200.

Racusen, D. \& N. Calvanico. 1964. Preparative electrophoresis on polyacrylamide gel. Anal. Biochem. 7: 62-66.

Roche, J. 1950. In The Enzymes. J. B. Sumner \& K. Myrback, Eds., I: 473-510. Academic Press, Inc., New York, N. Y.

Sawant, P. L., I. D. Desal \& A. L. Tappel. 1964a. Factors affecting the lysosomal membrane and availability of enzymes. Arch. Biochem. 105, 247-253.

Sawant, P. L., S. Shibko, U. S. Kumta \& A. L. Tappel. 1964b. Isolation of rat liver lysosomes and their general properties. Biochim. Biophys. Acta 85 , 82-92.

ShibKo, S. \& A. L. TAPPEL. 1963. Acid phosphatases of the lysosomal and soluble fractions of rat liver. Biochim. Biophys. Acta 73: 76-86.

Shibko, S. \& A. L. TAPPEL. 1964. Distribution of esterases in rat liver. Arch. Biochem. 106: $259-266$.

ShinowarA, G., L. Jones \& H. Reinhart. 1942. The estimation of serum inorganic phosphate and acid and alkaline phosphatase activity. J. Biol. Chem. 142: 921-933.

Sioma Chemicat. Company. 1963. Sigma Technical Bulletin No. 104. St. Louis, Mo.

Stapels, R. C., W. J. McCarthy \& M. A. Stahmann. 1965. Heat stabilities of acid phosphatases from Pinto bean leaves. Science 149: 1248-1249.

Swanson, M. 1955. In Methods in Enzymology. Vol. II. S. P. Colowick \& N. O. Kaplan, Eds., II: 541-546. Academic Press, Inc., New York, N. Y.

Ugazio, G. \& P. Pani. 1963. Differential release of bound hydrolases from rat liver lysosomes treated by a non-ionic surface active substance. Exp. Cell Res. 31 : 424-427.

Van Lancker, J. L. 1964. Fed. Proc. 23 : 1050-1052.

VAN LANCKER, J. L. \& D. G. SEMPOUX. 1958. Regeneration of various cellular components in rat livers after subtotal hepatectomy. Arch. Biochem. 77, 129-137.

Walkinshaw, C. H. \& J. L. Van LanCKeR. 1964. Molecular mechanisms of liver regeneration. II. Intracellular distribution of biochemical markers in normal and regenerating liver. Lab. Invest. 13: 513-523.

Weissmann, B., G. Rowin, J. Marshall \& D. Friederici. 1967. Mammalian a-acetylglucosaminidase. Enzymic properties, tissue distribution, and intracellular localization. Biochemistry (Wash.) 6: 207-214.

Wildums, P. H. \& R. C. Staples. 1964. Acid phosphatases from healthy and rust infected Pinto bean leaves. Contrib. Boyce Thompson Inst. 22, 269-282.

\section{Discussion of the Paper}

C. DE Duve: Dr. Allen, have you explored the possibility of a precursorproduct relationship between the two acid phosphatases? Partial proteolysis, a process believed to take place within lysosomes, could be responsible for the physical changes you have described. Have you studied the effect of autolysis on the ratio of the two activities? 
Dr. Allen: We've not studied the effect of autolysis on the ratios. We have looked at autolysis in terms of electrophoretic phenomenon and, unfortunately, we cannot detect in these experiments any conversion of bound-to-soluble enzyme. This is a very intriguing point, and we would like to understand it. We simply can't.

DR. AMINoff (University of Michigan, Ann Arbor, Mich.): Might I suggest that, rather than proteolytic release, you could be adding a sugar, making it soluble.

Dr. Allen: Adding a sugar and thereby solublizing it. Well, these are of course, possibilities that have occurred to us in terms of the electrophoretic studies. It would take only a very minor difference in charge-the association of enzyme with substrate, perhaps-to give rise to these differences. However, I would point out that the binding between this bound phosphatase in membrane is very tight indeed. You simply cannot shake it off by any physical treatment we have that does not completely destroy the enzyme. 